\title{
Article \\ Neuroblastoma Invasion Strategies Are Regulated by the Extracellular Matrix
}

\author{
Cian Gavin ${ }^{1}$ (D), Nele Geerts ${ }^{1}$, Brenton Cavanagh ${ }^{2}$, Meagan Haynes ${ }^{3}$, C. Patrick Reynolds ${ }^{4,5}$, \\ Daniela Loessner 6,7 ${ }^{(\mathbb{D}}$, Andrew J. Ewald ${ }^{3,8}$ and Olga Piskareva $1,9,10, * \mathbb{D}$
}

1 Cancer Bio-Engineering Group, Department of Anatomy and Regenerative Medicine, RCSI University of Medicine and Health Sciences, Dublin D02 YN77, Ireland; ciangavin@rcsi.com (C.G.); nelegeerts@rcsi.com (N.G.)

2 Cellular and Molecular Imaging Core, RCSI University of Medicine and Health Sciences, Dublin D02 YN77, Ireland; brentoncavanagh@rcsi.com

3 Center for Cell Dynamics, Department of Cell Biology, School of Medicine, Johns Hopkins University, Baltimore, MD 21205, USA; mhayne11@jhmi.edu (M.H.); andrew.ewald@jhmi.edu (A.J.E.)

4 Cancer Center, School of Medicine, Texas Tech University Health Sciences Center, Lubbock, TX 79416, USA; patrick.reynolds@ttuhsc.edu

5 Departments of Pediatrics and Internal Medicine, School of Medicine, Texas Tech University Health Sciences Center, Lubbock, TX 79416, USA

6 Departments of Chemical Engineering and Materials Science and Engineering, Faculty of Engineering, Monash University, Melbourne, VIC 3800, Australia; daniela.loessner@monash.edu

7 Department of Anatomy and Developmental Biology, Faculty of Medicine, Nursing and Health Sciences, Monash University, Melbourne, VIC 3800, Australia

8 Sidney Kimmel Comprehensive Cancer Center, Cancer Invasion and Metastasis Program, Department of Oncology, School of Medicine, Johns Hopkins University, Baltimore, MD 21205, USA

9 School of Pharmacy and Biomolecular Sciences, RCSI University of Medicine and Health Sciences, Dublin D02 YN77, Ireland

Citation: Gavin, C.; Geerts, N.; Cavanagh, B.; Haynes, M.; Reynolds, C.P.; Loessner, D.; Ewald, A.J.; Piskareva, O. Neuroblastoma Invasion Strategies Are Regulated by the Extracellular Matrix. Cancers 2021, 13, 736. https://doi.org/10.3390/ cancers13040736

Academic Editors: Alice L. Yu and Shweta Joshi

Received: 5 January 2021

Accepted: 4 February 2021

Published: 10 February 2021

Publisher's Note: MDPI stays neutral with regard to jurisdictional claims in published maps and institutional affiliations.

10 National Children's Research Centre, Our Lady's Children's Hospital Crumlin, Dublin D12 8MGH, Ireland

* Correspondence: olgapiskareva@rcsi.com

Simple Summary: Paediatric cancer research in general and neuroblastoma, in particular, has minimal preclinical models of metastasis. As $50 \%$ of primary neuroblastomas have already metastasised at the time of diagnosis, it is important to develop models to understand the molecular mechanisms of neuroblastoma metastasis. Here, we describe a novel patient-derived xenograft (PDX)- and cell line-based organoid model. We found that the extracellular matrix (ECM) composition influenced the growth, viability and local invasion of organoids. PDX-derived neuroblastoma organoids displayed four various invasion phenotypes which were dependent on the local microenvironment, while cell lines were more restricted in their invasion strategies. These data support the use of organoid cultures for studying the biology and molecular basis of neuroblastoma invasion into normal tissues.

Abstract: Neuroblastoma is a paediatric malignancy of the developing sympathetic nervous system. About half of the patients have metastatic disease at the time of diagnosis and a survival rate of less than $50 \%$. Our understanding of the cellular processes promoting neuroblastoma metastases will be facilitated by the development of appropriate experimental models. In this study, we aimed to explore the invasion of neuroblastoma cells and organoids from patient-derived xenografts (PDXs) grown embedded in 3D extracellular matrix (ECM) hydrogels by time-lapse microscopy and quantitative image analysis. We found that the ECM composition influenced the growth, viability and local invasion of organoids. The ECM compositions induced distinct cell behaviours, with Matrigel being the preferred substratum for local organoid invasion. Organoid invasion was cell line- and PDXdependent. We identified six distinct phenotypes in PDX-derived organoids. In contrast, NB cell lines were more phenotypically restricted in their invasion strategies, as organoids isolated from cell line-derived xenografts displayed a broader range of phenotypes compared to clonal cell line clusters. The addition of FBS and bFGF induced more aggressive cell behaviour and a broader range of phenotypes. In contrast, the repression of the prognostic neuroblastoma marker, $M Y C N$, resulted in less aggressive cell behaviour. The combination of PDX organoids, real-time imaging and the 
novel 3D culture assays developed herein will enable rapid progress in elucidating the molecular mechanisms that control neuroblastoma invasion.

Keywords: neuroblastoma; organoids; 3D invasion assay; invasion phenotype; extracellular matrix environment (ECM)

\section{Introduction}

Neuroblastoma (NB) is the most common solid tumour in children [1,2]. At the time of diagnosis, metastatic spread is seen in half of the patients with primary neuroblastomas, which are in a high-risk category. Despite an intensive multimodal treatment regime, $50-60 \%$ of high-risk patients will relapse, which usually occurs within two years of diagnosis [3].

The spread of tumour cells, believed to account for up to $90 \%$ of cancer-related morbidities [4], is a heterogenous multistep process that is yet to be fully understood. The concept of cancer cell invasion is an adaptive and dynamic process that depends on various structural, molecular and microenvironmental conditions and as such requires adequate experimental models. Our understanding of this process in NB is limited in part due to a lack of appropriate model systems [5].

To date, studies investigating NB cell migration and invasion have relied on the widely used transwell and scratch wound assays that are easy to carry out at low cost. These assays have limitations which lead us to assess their effectiveness for modelling NB invasion and metastasis. First and foremost is that both assays involve the use of cancer cells grown in 2D monolayer cultures. These cultures fail to accurately recapitulate the 3D architecture of solid tumours, where malignant cells are heterogeneously exposed to different biochemical (nutrients, oxygen) and biophysical (stiffness) properties of the microenvironment. Furthermore, 2D cultures result in cellular homogeneity and hence are disadvantageous in modelling intratumour heterogeneity [6]. The lack of appropriate model systems to investigate local tumour cell invasion in NB prompted us to use a 3D in vitro invasion assay using patient-derived materials.

Subpopulations of malignant cells within a tumour display different phenotypic features, including cell morphology, motility, gene expression, drug resistance and metastatic potential [7]. This is known as intratumour heterogeneity, a hallmark of all malignancies, including $\mathrm{NB}$, and it is essential that preclinical disease models maintain this cellular heterogeneity. In the past, the most widely used models of high-risk NB were cancer cell lines, subcutaneous xenograft tumours derived from these cell lines, and genetically engineered mouse models, all of which have major limitations in maintaining intratumour heterogeneity. Cell lines are derived through clonal expansion of tumour cells, whereby those that survive in culture have up-regulated pro-survival genes. This results in a homogeneous population of cells and is among the reasons that cell lines often fail to predict the clinical efficacy of targeted anti-cancer therapies used in clinical trials. Despite this, in $2016,82 \%$ of published preclinical studies employed cell line-derived tumour models [5,8]. On the other hand, genetically engineered mouse models are often developed under the control of a specific oncogenic driver $(M Y C N, A L K)$ and hence do not capture the genetic diversity of human NB, which has many oncogenic drivers, including copy number alterations, chromosomal imbalances and TERT rearrangements [9]. These limitations are partially overcome by using patient-derived xenograft (PDX) models, which are created by the direct transplantation of human tumour material into immunodeficient mice and maintained by in vivo passaging [10]. Unlike the aforementioned approaches, PDXs maintain the histopathological features, genetic/epigenetic characteristics and anti-cancer drug sensitivities of their parental tumours [11-16]. Thus, PDXs, as a model system, maintain interpatient and intratumour heterogeneity. Because patient-derived NB tissue is scarce, PDXs provide a particularly relevant source of native tumour tissue for biological studies. 
Here, we report a 3D in vitro model of local tumour invasion in NB. We maximise the experimental yield of PDXs by isolating tumour organoids and growing them in hydrogel-based 3D models that mimic the extracellular matrix (ECM). We show that the ECM composition modifies the growth, migration, viability and local invasion of NB organoids by performing real-time 3D culture assays. Lastly, we benchmark NB organoids isolated from PDXs against clonal expansion of cell lines and cell line-derived xenografts and investigate the role of tumour-biological factors (soluble factors, MYCN).

\section{Results}

\subsection{Cell Invasion Strategies of NB Organoids in ECM-Mimicking Matrices}

To investigate the effect of the local ECM microenvironment on the invasive behaviour of organoids derived from human PDXs, we performed time-lapse microscopy of NB organoids embedded in 3D ECM cultures over $96 \mathrm{~h}$ (Figure 1A). We observed that NB cells displayed a spectrum of distinct behaviours within the organoid populations; representative images of each are shown in Figure 1B. To classify the observed phenotypes, we used previously published terminology that is based on the visual appearance of organoids and the presence and cellular distribution of actin filaments [17-24]. NB organoids commonly invaded as collective strands where adhesion between neighbouring cells was maintained. Confocal imaging confirmed the presence of one or several actin-rich protrusions indicative of cancer cells with mesenchymal traits. Thus, we termed this cellular strategy of invasion "collective mesenchymal". We also observed collective strand invasion in "elongated" organoids, when no multicellular branching was documented but cells within these organoids migrated in a common direction with a leading multicellular stream. Therefore, this phenotype may be molecularly distinct from the collective mesenchymal phenotype. In comparison, collective mesenchymal organoids extended their multicellular strands in multiple directions, and these strands commonly branched (Figure 1B).

We identified organoids with dispersed cells extending neurite-like processes into the ECM and termed this phenotype "neuronal". This cellular strategy of invasion was morphologically comparable to that seen in glioma, where cells invade as a collective network with transient cell-cell interactions both in 3D in vitro and in vivo models [22,23]. We also identified organoids that maintained a round central cell mass while extending long thin protrusions into the ECM and termed this phenotype "protrusive". The radial protrusions observed were actin-rich and often without nuclei, which may be unique to NB organoids (Figure 1B). When nuclei were seen within these protrusions, they were individually migrating or loosely followed by multicellular streams.

In addition to the invasive phenotypes described above, phenotypic heterogeneity was also seen in non-invasive organoids. Organoids that maintained a round cellular mass were termed "spheroid", while round organoids that developed a lumen were termed "cyst". In a similar experimental setup, cyst formation with a bi-layered epithelial structure was reported as a model of epithelial duct formation [25]. Although we did not investigate whether the cyst-like structures were bi-layered, we speculate, given the origin of NB, that they may in fact be neuroepithelial in nature. Neuroepithelial cyst formation in hydrogels has been described as a model of neural tube development in vivo [26]. Considering the multipotency of the cells of origin for NB, the distinct invasive behaviours observed in organoids isolated from PDXs suggests that the heterogeneity of NB is retained in our 3D approach. 
A

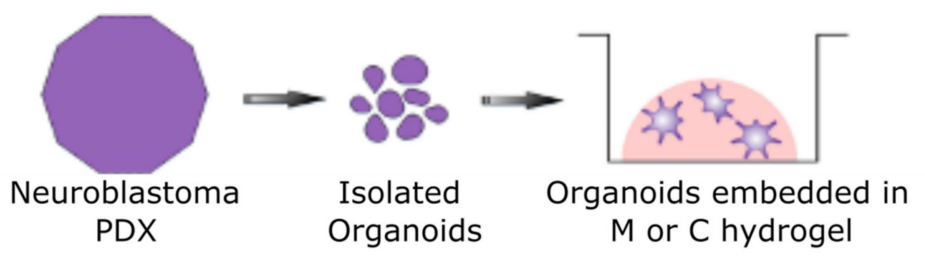

B
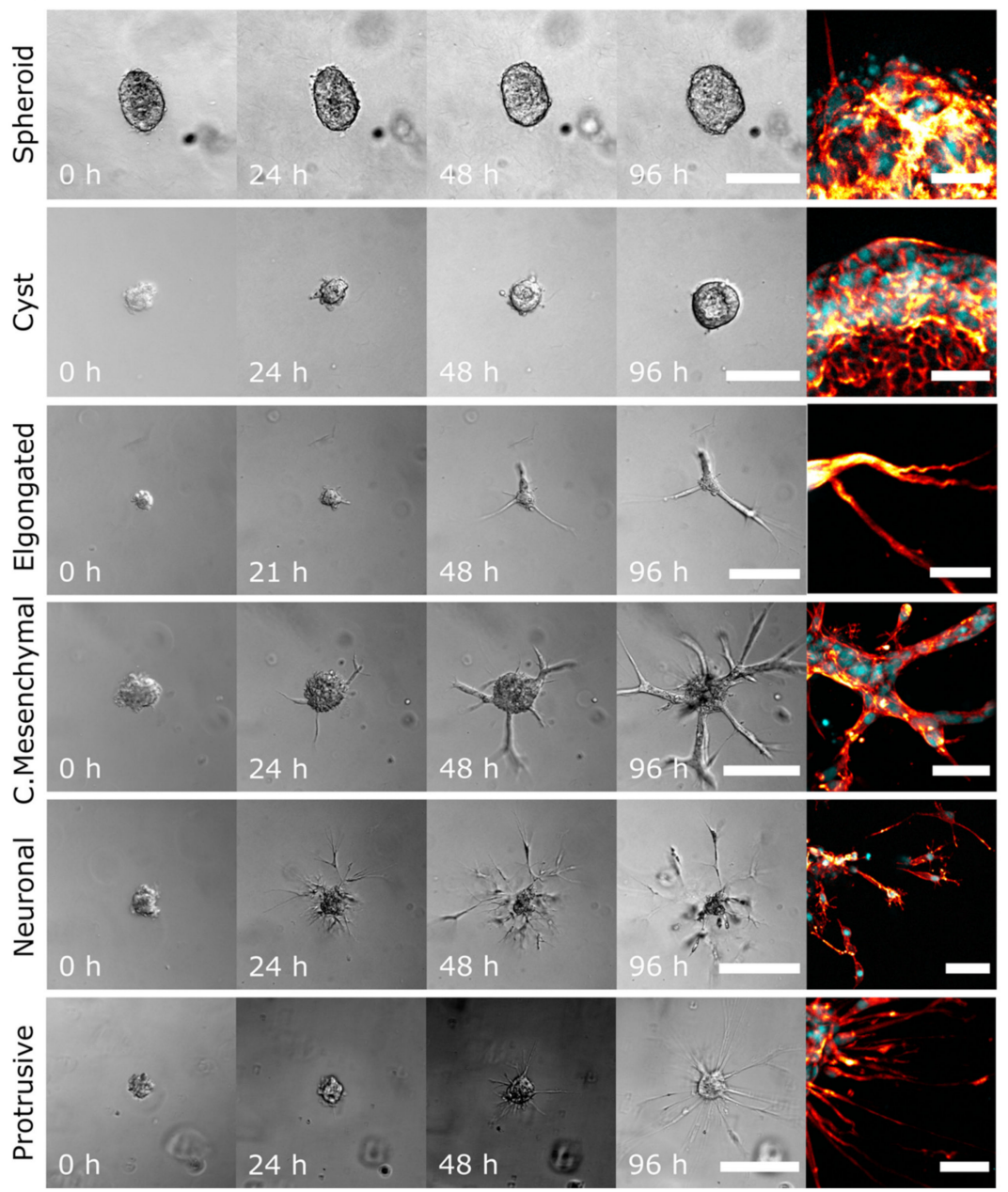

Figure 1. Neuroblastoma (NB) organoids are heterogenous and display a spectrum of distinct invasion strategies in 3D assays. (A) Schematic of isolation and 3D culture of human neuroblastoma clusters. Matrigel, M, Collagen, C hydrogels. (B) Representative DIC time-lapse and confocal images of organoids isolated from Felix-patient-derived xenograft (PDX) and grown in 3D extracellular matrix (ECM) cultures. Confocal images, taken on day 5 of 3D culture, show nuclei stained with DAPI (cyan) and actin filaments stained with phalloidin (red). Based on the morphology NB, organoids were classified as non-invasive (spheroid, cyst) or invasive (elongated, collective mesenchymal, neuronal or protrusive). For spheroid and cyst: DIC scale bars $=100 \mu \mathrm{M}$, confocal scale bars $=30 \mu \mathrm{M}$, elongated DIC scale bars $=150 \mu \mathrm{M}$, confocal scale bars $=30 \mu \mathrm{M}$. For all remaining DIC images: scale bars $=200 \mu \mathrm{M}$, confocal scale bars $=50 \mu \mathrm{M}$.

\subsection{Invasion of NB Organoids Depends on the PDX of Origin and ECM Composition}

To further elucidate the invasive behaviour of NB organoids, we isolated NB cells from four different PDXs, namely, 424x, 573x, 603x and Felix (Table 1, File S1) and embedded them into two different matrices (Matrigel, collagen type-I) for time-lapse microscopy analysis. Matrigel is primarily composed of laminin $(\sim 60 \%)$, collagen IV $(\sim 30 \%)$, nidogen $(\sim 5 \%)$, heparan sulphate proteoglycan (perlecan, $\sim 3 \%)$ and entactin $(\sim 1 \%)$ and contains 
undefined amounts of growth factors, including bFGF [27]. We used growth factor-reduced Matrigel to limit the impact of growth factors on cell invasion.

Table 1. Characteristics of NB PDXs used.

\begin{tabular}{|c|c|c|c|c|c|c|c|c|}
\hline PDX & $\begin{array}{c}\text { Risk } \\
\text { Classification }\end{array}$ & $\begin{array}{l}\text { Phase of } \\
\text { Therapy }\end{array}$ & Sample Type & Stage & $\begin{array}{l}M Y C N \\
\text { Status }\end{array}$ & $\begin{array}{c}A L K \\
\text { Status }\end{array}$ & $\begin{array}{c}\text { TERT } \\
\text { mRNA }\end{array}$ & Ref. \\
\hline COG-N-424x & High & DX & Tumour & 4 & Amp & WT & ++ & {$[15,28]$} \\
\hline COG-N-573x & High & DX & $\mathrm{BM}$ & 4 & Amp & WT & ++ & [28] \\
\hline COG-N-603x & High & DX & Tumour & 4 & Amp & WT & +++ & $\begin{array}{c}{[15,28,} \\
29]\end{array}$ \\
\hline Felix-PDX & High & PD-PM & Blood & 4 & $\begin{array}{l}\text { Non- } \\
\text { Amp }\end{array}$ & $\begin{array}{c}\text { ALK } \\
\text { F1245C }\end{array}$ & ++ & $\begin{array}{c}{[15,28,} \\
30]\end{array}$ \\
\hline
\end{tabular}

DX, diagnosis; BM, bone marrow; PD, progressive disease; PM, post-mortem; Amp, amplified; WT, wild type; +, low; ++, intermediate; +++ , high.

The extent of invasion in both 3D ECM cultures was PDX-dependent. 424x organoids exclusively formed spheroids in both matrices (Figure 2A) and hence were non-invasive. To confirm our microscopic observations, we measured the circularity of 424x organoids and found high circularity values (Figure $2 \mathrm{~B}$ ) and a predominant spheroid phenotype (Figure 2C). We identified a small number of $424 x$ organoids with transient cellular protrusions, reflected by lower circularity values (Figure S1.2 in File S1).

$573 x$ organoids also predominantly formed non-invasive spheroids in both Matrigel $(86 \%)$ and collagen $(93 \%)$ matrices (Figure 2A). However, a small proportion of 573x organoids invaded both matrices and were classified as neuronal due to the presence of neurite-like processes (Figure S1.3 in File S1). 573x organoids began to invade within $24 \mathrm{~h}$. We also found one elongated organoid in Matrigel. Plotting the circularity of $573 x$ organoids over time supported our microscopic observations. The vast majority formed spheroids rapidly, resulting in a significantly increased circularity after $24 \mathrm{~h}$ in both matrices (Figure 2B). As the smaller proportion of invasive organoids continued to lose their circularity, the degree of significance declined over time in both matrices; however, Matrigel contained more invasive organoids (14\%) compared to collagen (7\%) (Figure 2C). The exposure to different ECM compositions did not induce distinct phenotypes in 573x organoids.

In contrast, $603 x$ organoids displayed an ECM-dependent invasion that was phenotypically heterogeneous (Figure 2A). 603x organoids preferentially invaded Matrigel, with 56\% of organoids classified as invasive, compared to collagen, in which only $22 \%$ of organoids were invasive. This preference was confirmed by their circularity, with most $603 x$ organoids rapidly losing their circularity in Matrigel, significantly after $48 \mathrm{~h}$ (Figure 2B). In collagen, organoid circularity increased over $48 \mathrm{~h}$, followed by a significant decrease up to $96 \mathrm{~h}$. We found a greater variety of organoid phenotypes in Matrigel, where all six morphological phenotypes were identified, compared to collagen, with only four phenotypes (Figure 2C). Although there was no significant difference in the relative growth of $603 x$ organoids between both matrices, the greatest growth occurred in Matrigel (Figure S1.4 in File S1).

Felix organoids also displayed a profound preference for Matrigel when invading their local ECM (Figure 2A), with 50\% of organoids being invasive. Their circularity showed a bimodal behaviour in Matrigel, with half of Felix organoids losing their circularity as they invaded their local ECM (Figure 2B). In contrast, the majority of Felix organoids grown in collagen maintained high circularity values, indicative of the predominant noninvasive spheroid $(74 \%)$ and cyst $(17 \%)$ phenotypes (Figure $2 \mathrm{C}$ ). The relative growth of Felix organoids supported Matrigel as a promoter of invasion, with a significantly increased growth compared to collagen (Figure 2D, Figure S1.5 in File S1) 


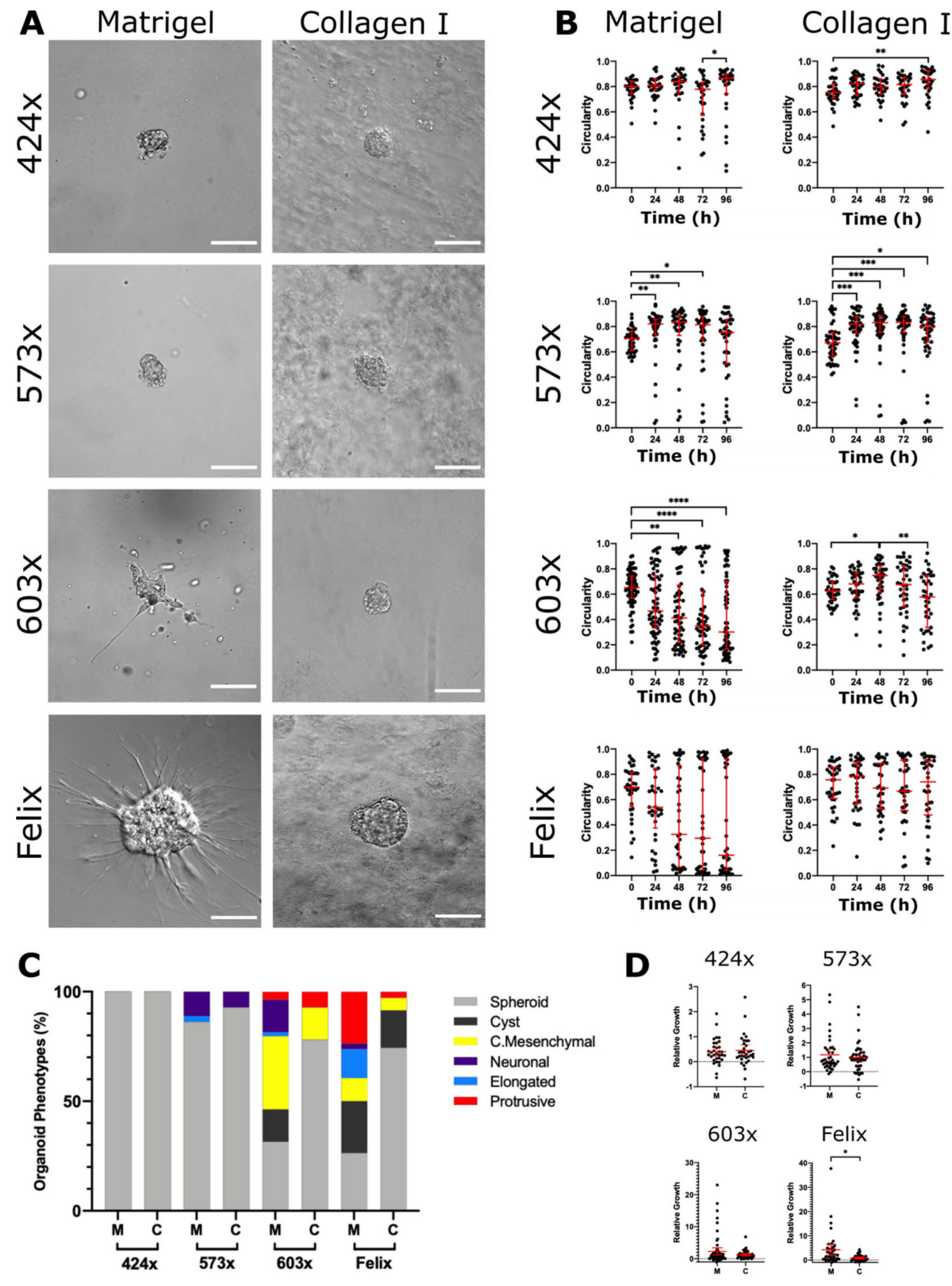

Figure 2. ECM microenvironments modulate the pattern of collective invasion and local dissemination in neuroblastoma cells. (A) Representative DIC images of organoids isolated from neuroblastoma PDXs and grown in 3D ECM cultures at $96 \mathrm{~h}$. Based on morphology NB, organoids were classified as non-invasive (spheroid, cyst) or invasive (elongated, collective mesenchymal, neuronal or protrusive). For spheroid and cyst: DIC scale bars $=100 \mu \mathrm{M}$; elongated scale bars $=150 \mu \mathrm{M}$ DIC. For other DIC images: scale bars $=200 \mu \mathrm{M}$. (B) Organoid circularity was measured at $96 \mathrm{~h}$ in Matrigel and collagen (Kruskal-Wallis and Dunn's post-hoc tests; horizontal bars represent median and interquartile range). (C) Bar charts represent phenotype classifications. (D) The relative growth of organoids was calculated by dividing the difference in area between $0 \mathrm{~h}$ and $96 \mathrm{~h}$ by the area at $0 \mathrm{~h}$. Each dot represents the relative growth of one organoid (Matrigel: $\mathrm{n}=32 \mathrm{for} 424 \mathrm{x}$, $n=41$ for $573 x, n=3$ for $603 x, n=38$ for Felix; collagen: $n=35$ for $424 x, n=46$ for $573 x, n=40$ for $603 x, n=36$ for Felix). Error bars indicate the mean $\pm 95 \%$ confidence interval. Asterisks indicate statistical significance obtained using BrownForsythe ANOVA with T3 Dunnett post-hoc test (ns, not significant, ${ }^{*} p<0.05,{ }^{* *} p<0.01,{ }^{* * *} p<0.001,{ }^{* * * *} p<0.0001$ ). Scale bars $=100 \mu \mathrm{M}$. 


\subsection{Invasion, Growth and Viability of NB Organoids Depend on Soluble Factors}

Next, we explored the impact of serum and growth factors in the microenvironment on the behaviour of organoids. To investigate whether these nutrients were essential for aggressive behaviour, we selected Felix organoids due to their consistently invasive nature. Felix organoids were grown in two different matrices and their medium supplemented with FBS (10\%), basic fibroblast growth factor (bFGF/FGF-2; $2.5 \mathrm{nM}$ ) or both (FBS/bFGF). We performed time-lapse microscopy, 3D invasion assays and assessed their viability using ethidium homodimer to evaluate organoid responses to the different microenvironmental conditions.

The presence of FBS and bFGF induced diverse organoid phenotypes in both matrices tested (Figure 3A). In Matrigel, 37\% of organoids were classified as invasive in the presence of both FBS/bFGF, while only 12 or $13 \%$ of organoids were invasive when FBS or bFGF alone were present, respectively. In contrast, $56 \%$ of organoids had an invasive phenotype when both FBS/bFGF were present. Of note, the number of organoids in both matrices was relatively low. In the collagen matrix, invasive organoids were also absent upon bFGF treatment, while invasion was observed with FBS ( $24 \%$ of organoids) and FBS/bFGF treatment ( $20 \%$ of organoids).

The relative growth of Felix organoids showed a similar trend as the phenotype classifications, with organoids grown in both bFGF/FBS revealing the highest growth rate in both matrices (Figure 3B). In Matrigel, bFGF alone significantly increased organoid size compared to FBS alone. Conversely, both bFGF/FBS were required to promote organoid growth in collagen. Most organoids supplemented with FBS decreased in size, suggesting decreased cell viability (Figure 3B, data below dotted line). We confirmed the presence of non-viable cells using ethidium homodimer staining (Figure 3C). The treatment with both bFGF/FBS led to highly viable organoids in our 3D invasion assays. Overall, NB organoid cultures in Matrigel and the simultaneous presence of bFGF and FBS promoted an aggressive behaviour and local cell invasion.

\subsection{Neuroblastoma Cell Lines Display ECM-Independent Invasion Strategies}

We next investigated the invasion behaviour of commonly used NB cell lines (MYCN amplified (MNA) and non-amplified (nMNA); Table S2.1 in File S2) in Matrigel and collagen (Figure 4). The cell line clusters successfully developed from single cells in both matrices, as determined by time-lapse microscopy. Most cell lines formed clusters of varying sizes, regardless of the matrix (Table 2). We observed only two distinct invasive phenotypes, collective mesenchymal and neuronal. We regarded two of the MNA cell lines, Kelly and CHP212, as non-invasive because they exclusively formed spheroids (Figure 4A). Conversely, Lan1 (MNA) and SH-SY5Y (nMNA) cells had invasive phenotypes.

SH-SY5Y cell clusters were mostly invasive in both matrices (61\% in Matrigel and 95\% in collagen) (Figure 4C). SH-SY5Y cells exclusively displayed the collective mesenchymal mode of invasion, which was identified by the presence of multicellular branches with protrusive tips.

Lan-1 cell clusters were predominantly classified as invasive neuronal in Matrigel $(73 \%)$, whereas clusters mostly formed non-invasive spheroids in collagen (82\%) (Figure 4C). This cell line behaved similarly to the PDX NB organoids in that regard, showing increased invasion in Matrigel. Our microscopic observations were confirmed by measuring the circularity of clonal cell clusters over time (Figure 4B). The non-invasive cell lines maintained high circularity values, while the invasive cell lines displayed decreased circularity.

Interestingly, the clonal clusters of the NB cell lines did not display the same phenotypic diversity as the PDX organoids in our 3D invasion assays. 
A
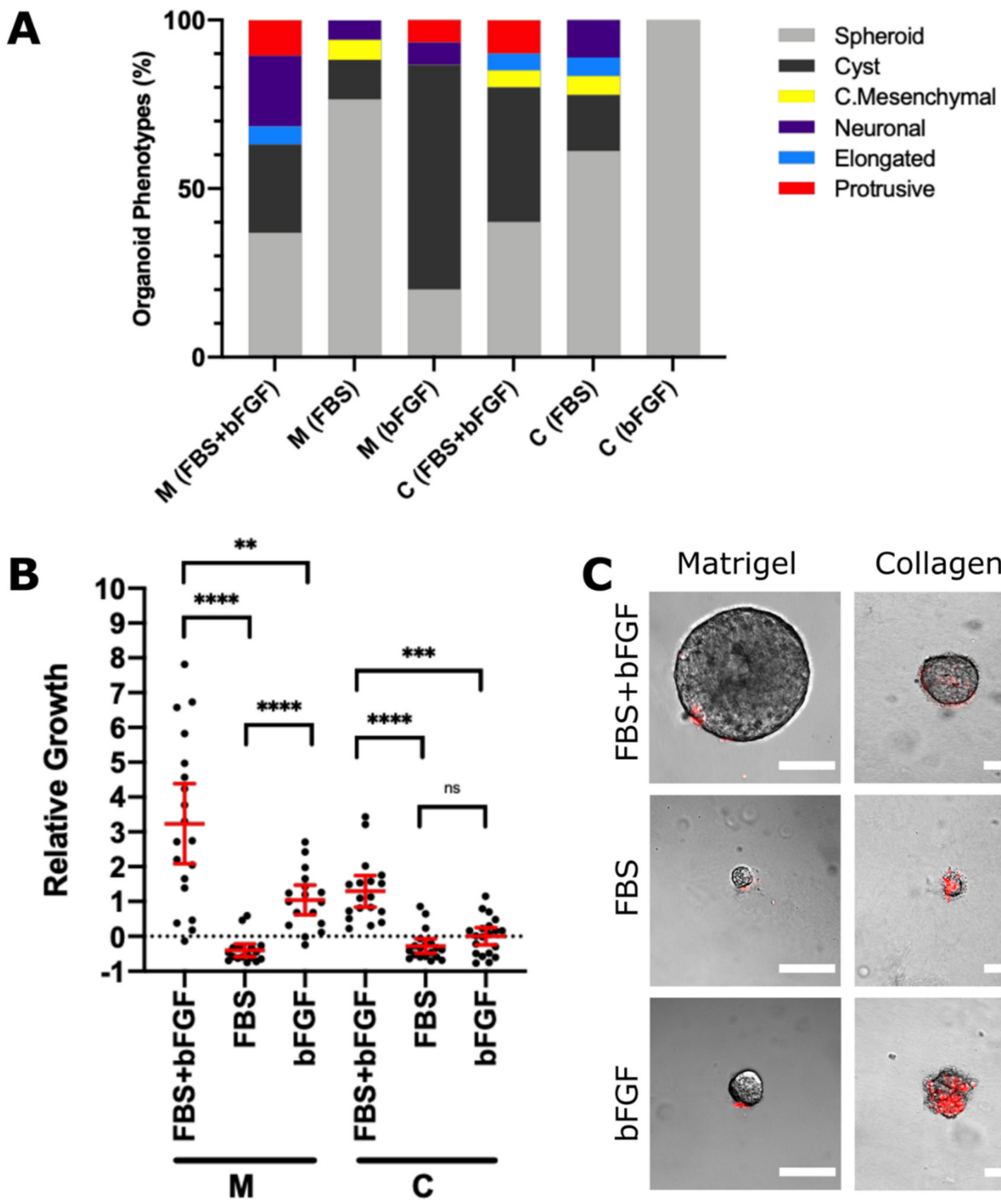

Collagen I
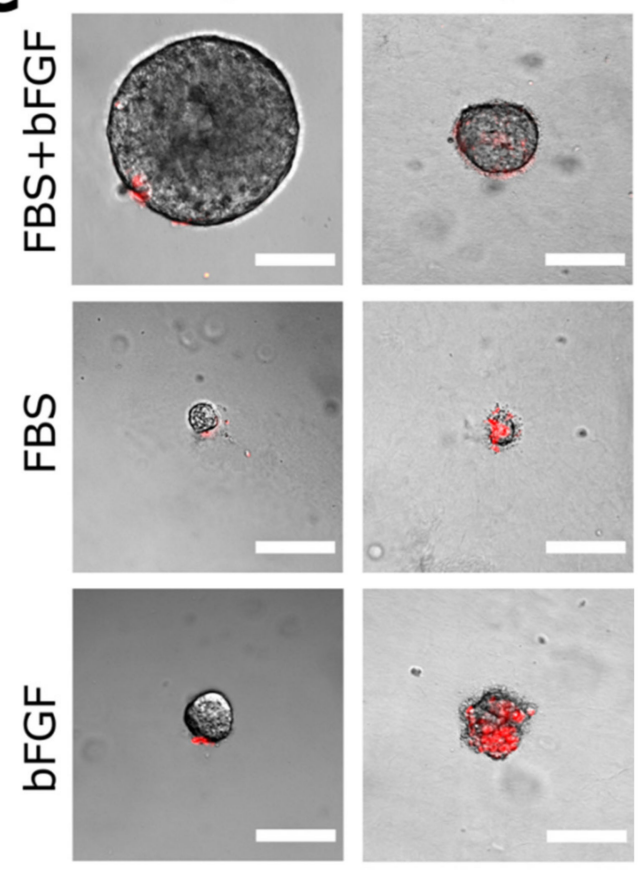

Figure 3. The invasion and growth of NB organoids is dependent on soluble factors in the microenvironment. (A) Felix-PDX organoids were cultured in Matrigel or collagen in the presence of FBS + bFGF, FBS or bFGF alone and corresponding bar charts representing phenotype classifications. (B) The relative growth of these organoids was calculated by dividing the difference in area between $0 \mathrm{~h}$ and $96 \mathrm{~h}$ by the area at $0 \mathrm{~h}$. (C) Representative images of EHD staining (dead cells: red) of organoids at $120 \mathrm{~h}$. Each dot represents the relative growth of one organoid (Matrigel: $n=19$ in FBS/bFGF, $n=17$ in FBS, $n=15$ in bFGF. Collagen: $n=20$ in FBS/bFGF, $n=17$ in FBS, $n=14$ in bFGF). Error bars indicate the mean $\pm 95 \%$ confidence interval. Asterisks indicate statistical significance obtained using Brown-Forsythe ANOVA with T3 Dunnett post-hoc test (ns, not significant, ${ }^{*} p<0.05,{ }^{* *} p<0.01,{ }^{* * *} p<0.001,{ }^{* * * *} p<0.0001$ ). Scale bars $=100 \mu \mathrm{M}$. 


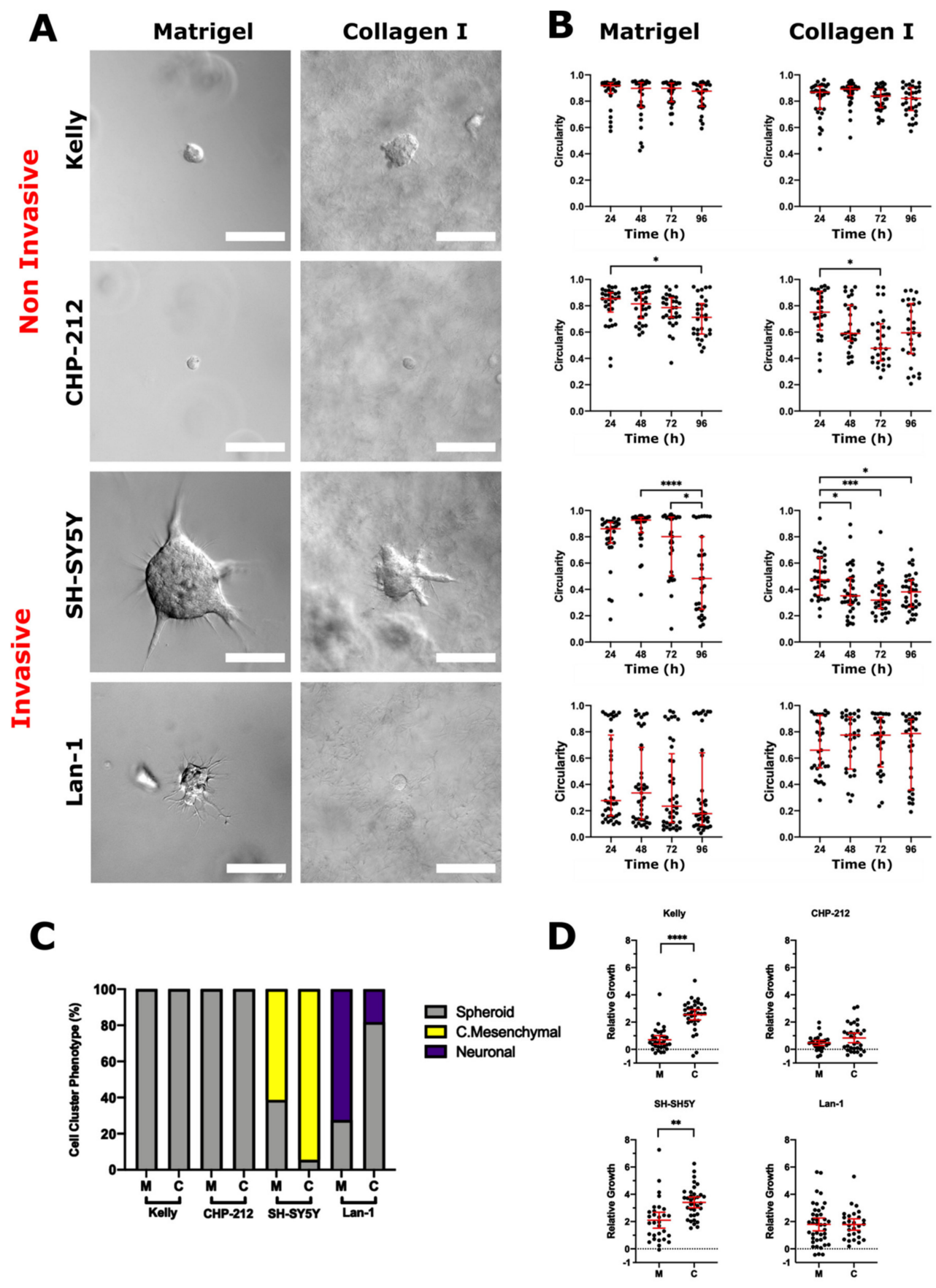

Figure 4. ECM microenvironments modulate the pattern of collective invasion and local dissemination in human neuroblastoma cells. (A) Representative DIC images of NB cell clusters grown in 3D ECM cultures at $96 \mathrm{~h}$. Based on the morphology NB cell clusters were classified as non-invasive (spheroid, cyst) or invasive (elongated, collective mesenchymal, neuronal or protrusive). (B) Cell cluster circularity was measured at $96 \mathrm{~h}$ in Matrigel and collagen (Kruskal-Wallis and Dunn's post-hoc tests; horizontal bars represent median and interquartile range). (C) Corresponding bar charts represent phenotype classifications. (D) The relative growth of these clusters was calculated by dividing the difference in area between $0 \mathrm{~h}$ and $96 \mathrm{~h}$ by the area at $0 \mathrm{~h}$. Each dot represents the relative growth of one cell cluster (Matrigel: $n=31$ for Kelly, $n=30$ for CHP-212, $n=30$ for SH-SY5Y, $n=41$ for Lan-1; collagen: $n=30$ for Kelly, $n=29$ for CHP-212, $n=34$ for SH-SY5Y, $n=34$ for Lan-1). Error bars indicate the mean $\pm 95 \%$ confidence interval. Asterisks indicate statistical significance obtained using Brown-Forsythe ANOVA with T3 Dunnett post-hoc test (ns, not significant, ${ }^{*} p<0.05,{ }^{* *} p<0.01,{ }^{* * *} p<0.001$, **** $p<0.0001)$. Scale bars $=30$ (Kelly, CHP-212), 50 (Lan-1) and $100 \mu \mathrm{M}$ (SH-SY5Y). 
Table 2. The approximate timepoints at which NB invasion started in Matrigel and collagen matrices.

\begin{tabular}{lll}
\hline \multicolumn{1}{c}{ Cell Line/Organoid } & \multicolumn{1}{c}{ Time } & \multicolumn{1}{c}{ (Hours) } \\
\hline SHEP-21N(MYCN-On/Off) & Matrigel & Collagen \\
\hline LAN-1 & $<24$ & $24-48$ \\
\hline SH-SY5Y & $<24$ & $48-72$ \\
\hline SH-SY5Y Organoids & $24-48$ & $48-72$ \\
\hline COG-N-573x & $<24$ & $48-72$ \\
\hline COG-N-603x & $<48$ & $<12 *$ \\
\hline COG-N-Felix & $<48$ & $<12 *$ \\
\hline$*$ primarily non-invasive & $<48$ & $>120^{*}$ \\
\hline
\end{tabular}

* primarily non-invasive.

\subsection{Expression Levels of MYCN Are Associated with Aggressive NB Behaviour}

Genomic amplification of $M Y C N$ occurs in approximately $20 \%$ of NBs and is associated with aggressive disease and poor outcome [31]. Elevated levels of $M Y C N$ expression may activate genes that drive aggressive cell behaviour. Therefore, we aimed to investigate whether elevated MYCN expression promotes the growth and invasion of NB cells. We embedded single SHEP-Tet21N cells that were continuously treated with doxycycline to repress the expression of MYCN [32] (MYCN-OFF) and untreated cells (MYCN-ON) in Matrigel and collagen matrices and determined clonal expansion and cell invasion by time-lapse microscopy over $96 \mathrm{~h}$ (Figure 5).

Cell clusters exclusively employed the collective mesenchymal strategy in both matrices (Figure 5A). However, the invasive behaviour appeared more aggressive in $M Y C N-O N$ cells. Furthermore, $\mathrm{MYCN-ON}$ cells formed significantly larger clusters compared to MYCN-OFF in both matrices (Figure 5B). Measuring the circularity of individual cell clusters confirmed our microscopic observations and illustrated the highly invasive nature of SHEP-Tet $21 \mathrm{~N}$ cells, regardless of the MYCN status. The vast majority of cell clusters lost their spherical morphology after $48 \mathrm{~h}$ (circularity < 0.4) in Matrigel (Figure 5C) and collagen (Figure 5D). This trend in circularity loss was similar in MYCN-ON and MYCN-OFF cells; however, the representative time-lapse and confocal micrographs depicted that invasion in fact was more aggressive when MYCN transcription is turned "ON" (Figure 5E). These results suggest that cells with high levels of MYCN display an aggressive behaviour in our 3D invasion assay. However, we found that NB organoids isolated from two of the MYCN-amplified PDXs (Figure 2C) did not display an invasive behaviour in our 3D assays, indicating that factors other than MYCN regulate the invasive phenotype.

\subsection{The In Vivo Tumour Microenvironment Fosters a Distinct Invasion Strategy in NB Cells}

Lastly, we explored whether the in vivo tumour microenvironment is sufficient to induce more diverse invasion strategies in NB cells. We produced SH-SY5Y cell xenografts and isolated organoids from the resulting tumours for our in vitro 3D invasion assays. The behaviour of these organoids was distinct (Figure 6A) from that of the SH-SY5Y cell clusters discussed above (Figure 4). In Matrigel, the majority of SH-SY5Y organoids isolated from the PDXs (76\%) resembled the protrusive phenotype (Figure 6A,C-E). Unlike the cell clusters, SH-SY5Y organoids were predominantly non-invasive in collagen, where $53 \%$ of organoids formed spheroids with no protrusions. However, we did also observe invasive organoids that employed both the protrusive and collective mesenchymal strategies of invasion in collagen. Measuring circularity confirmed a greater proportion of invasive organoids in Matrigel (Figure 6B); however, invasive organoids appeared less aggressive in collagen (Figure 6F). Overall, the in vivo tumour microenvironment promoted a distinct local invasion strategy of SH-SY5Y cells. 

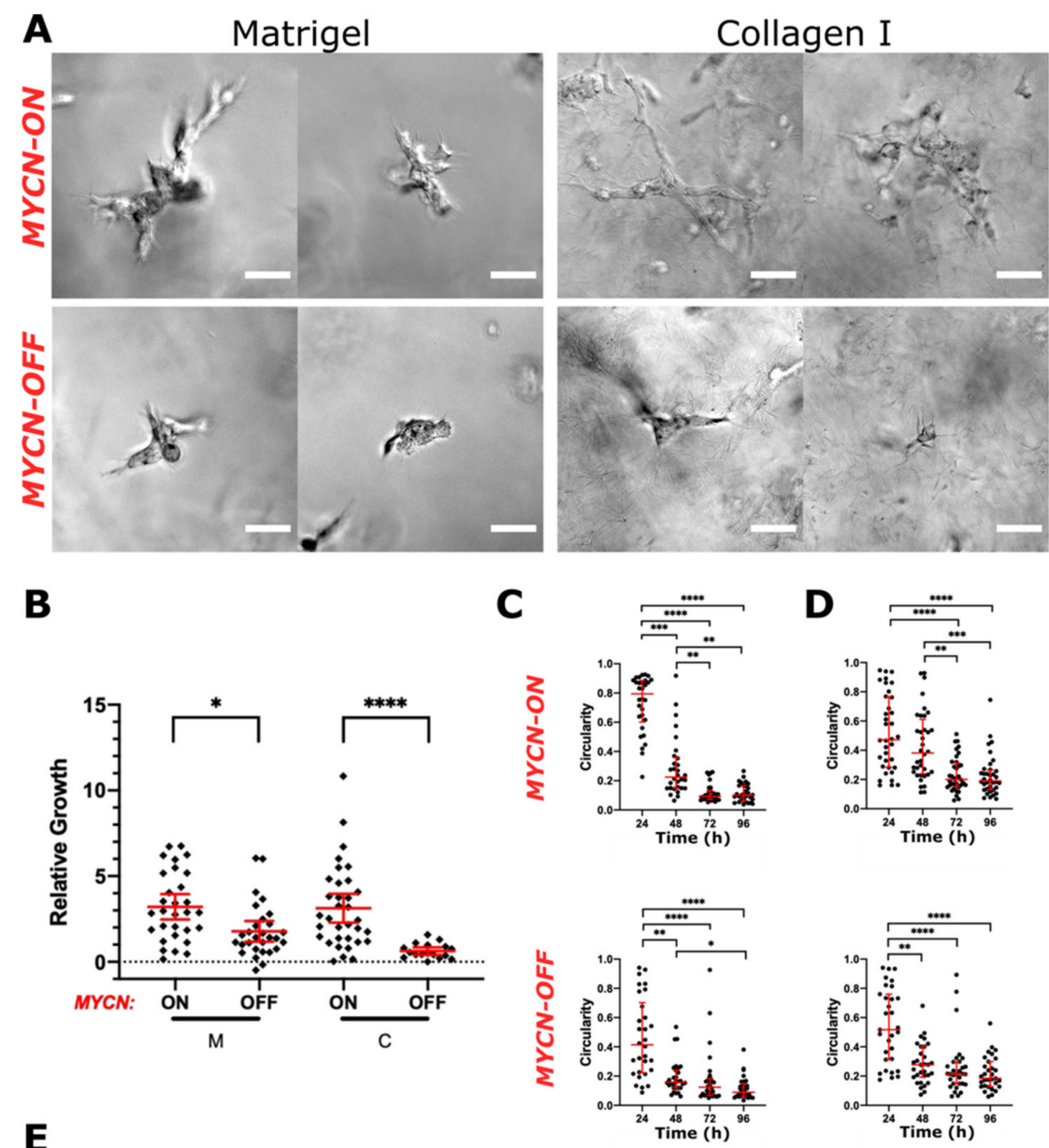

E

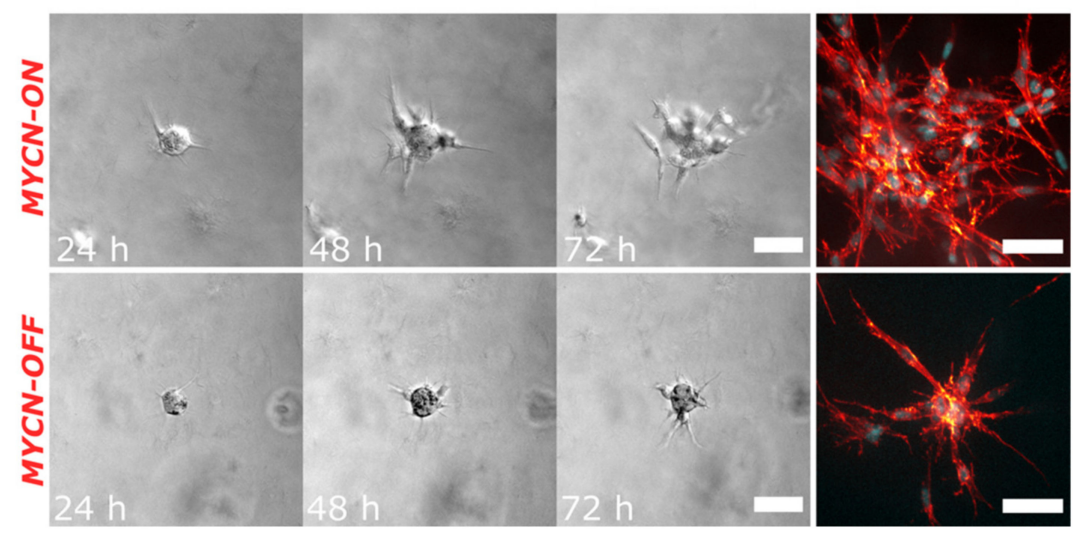

Figure 5. Repressing MYCN expression promotes less aggressive cell behaviour in SHEP-Tet21N cells. (A) Representative DIC images of untreated SHEP-Tet21N (MYCN-ON) and doxycycline-treated (MYCN-OFF) cells after $72 \mathrm{~h}$ in Matrigel and collagen. (B) Relative growth of organoids was calculated by dividing the difference in cluster area at $72 \mathrm{~h}$ compared to $24 \mathrm{~h}$, by the area at $24 \mathrm{~h}$ (Brown-Forsythe ANOVA with T3 Dunnett post-hoc tests; horizontal bars represent mean $\pm 95 \%$ confidence intervals). Circularity of MYCN-ON and MYCN-OFF cell clusters was measured at $72 \mathrm{~h}$ in Matrigel (C) and collagen (D) (Kruskal-Wallis and Dunn's post-hoc tests; horizontal bars represent median and interquartile range). (E) Representative DIC time-lapse and confocal micrographs (120 h) comparing SHEP-Tet21N cell clusters with MYCN-ON and MYCN-OFF; nuclei stained with DAPI (cyan) and F-actin stained with phalloidin (red). In all plots, each dot represents one cell cluster (MYCN-ON; $n=30$ in Matrigel, $n=34$ in collagen. MYCN-OFF; $n=29$ in Matrigel, $n=17$ in collagen) and asterisks indicate statistical significance $\left({ }^{*} p<0.05,{ }^{* *} p<0.01,{ }^{* * *} p<0.001,{ }^{* * * *} p<0.0001\right)$. Scale bars $=50 \mu \mathrm{M}$. 
A
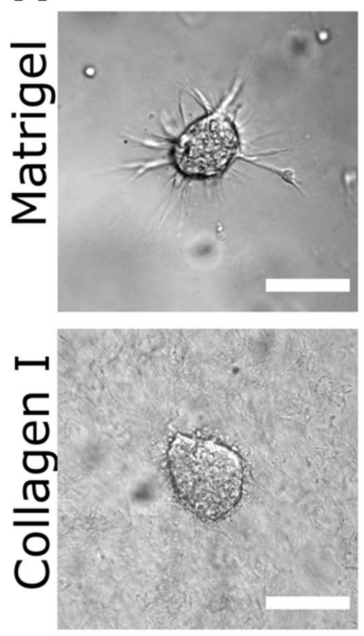

C

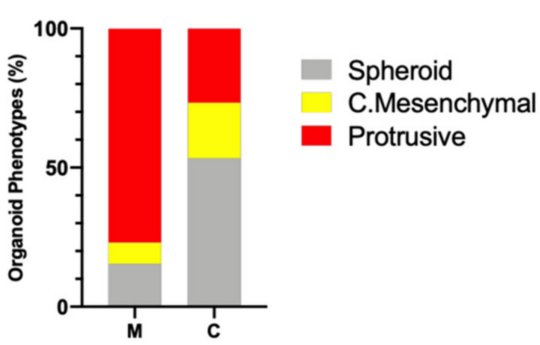

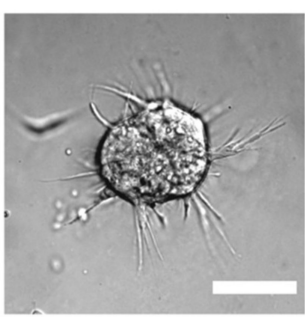

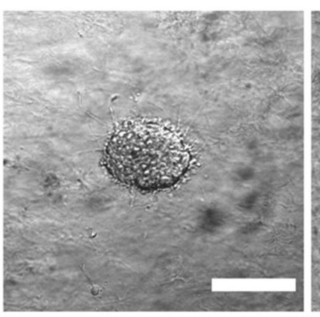

D

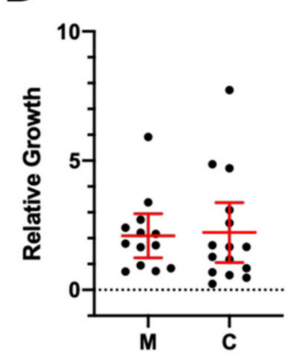

B
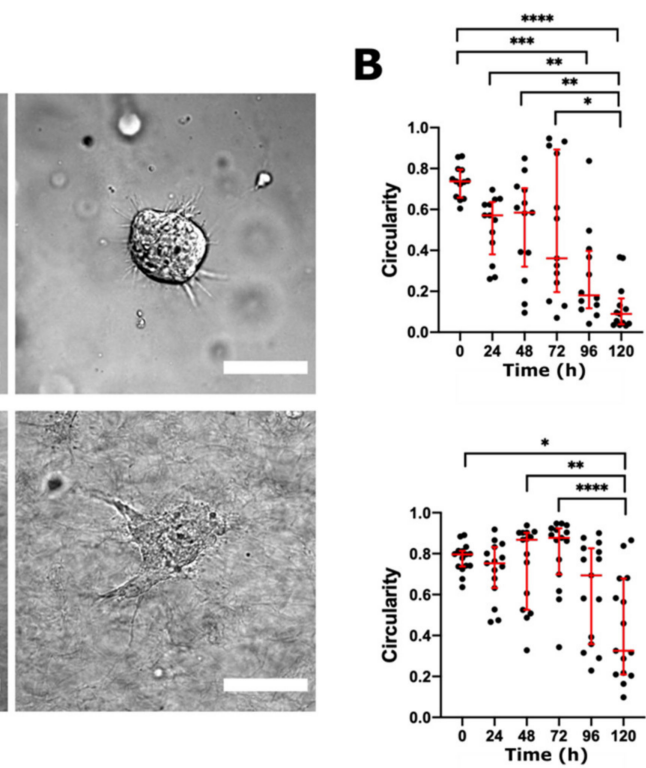

E

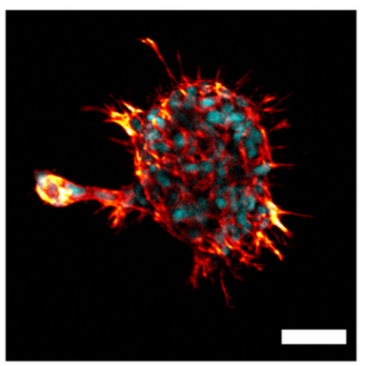

F
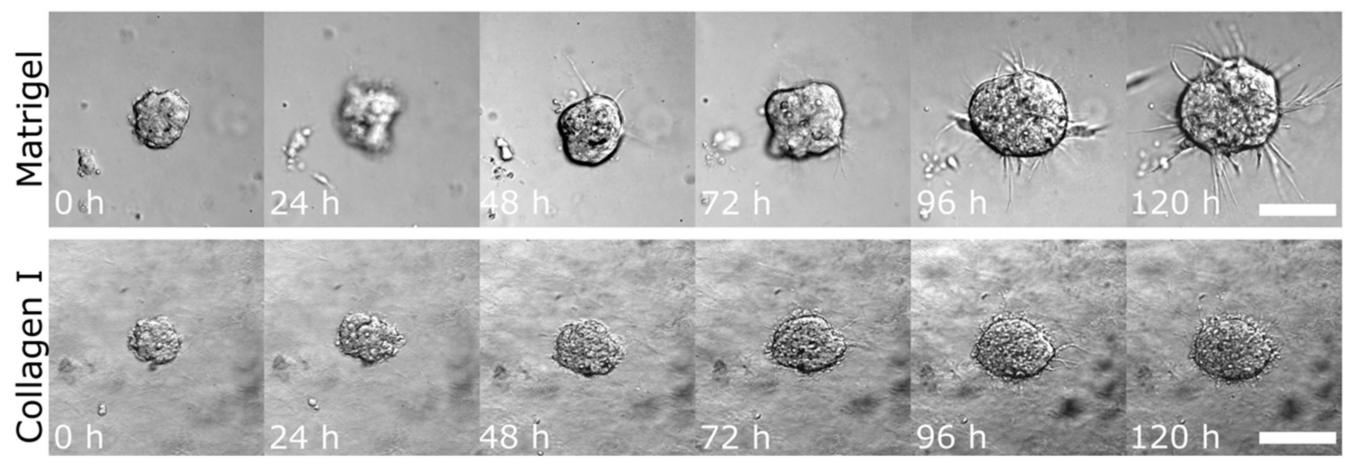

Figure 6. The invasive behaviour of SH-SY5Y cells is altered in response to an in vivo tumour microenvironment. (A) Representative DIC images of organoids isolated from SH-SY5Y xenografts after 5 days of culture in Matrigel and collagen. (B) Organoid circularity, where a value of 1.0 indicates a perfect circle, was measured to support microscopic observations of phenotypical changes in Matrigel and collagen (Kruskal-Wallis and Dunn's post-hoc tests; horizontal bars represent median and interquartile range). (C) Bar charts represent the proportion of organoids per phenotype classification. (D) The relative growth of organoids was calculated by dividing the difference in area between $0 \mathrm{~h}$ and $96 \mathrm{~h}$ by the area at $24 \mathrm{~h}$ (Brown-Forsythe ANOVA with T3 Dunnett post-hoc tests; horizontal bars represent mean $\pm 95 \%$ confidence intervals). (E) Representative confocal image of a "protrusive" SH-SY5Y organoid in Matrigel; nuclei stained with DAPI (cyan) and F-actin stained with phalloidin (red). (F) Representative DIC time-lapse images of protrusive invasion in Matrigel and collagen I over a $120 \mathrm{~h}$ period. In all plots, each dot represents one organoid ( $n=13$ in Matrigel, $n=15$ in collagen) and asterisks indicate statistical significance $\left({ }^{*} p<0.05,{ }^{* *} p<0.01,{ }^{* * *} p<0.001,{ }^{* * * *} p<0.0001\right)$. DIC scale bars $=100 \mu \mathrm{M}$, confocal scale bars $=50 \mu \mathrm{M}$. 


\section{Discussion}

3.1. NB Organoids Isolated from PDXs Are Phenotypically Heterogenous during Local ECM Invasion

NB cells employed distinct strategies to invade ECM-mimicking hydrogels (Figure 7). We identified four invasive phenotypes based on morphological changes over time. NB organoids commonly invaded as collective strands maintaining adhesions between neighbouring cells. Cells at the leading edge of these strands appeared mesenchymal-like due to the presence of one or several actin-rich protrusions, indicative of cells with mesenchymal traits and a "collective mesenchymal" invasion. Previous studies have described similar modes of multicellular migration where leading cells proteolytically degrade the ECM, creating a track that is widened by following cells [18]. Collective strands have been reported for breast cancer cells in 3D in vitro and in vivo models [17,19], for melanoma cells using intravital imaging [20] and clusters of circulating tumour cells have been identified in patients with metastatic disease [33]. In a small study of $28 \mathrm{NB}$ patients, one circulating tumour cell cluster was identified in a high-risk patient with distant lymph node metastasis [34]. We also observed collective strand invasion in our "elongated" organoids; however, this phenotype was molecularly distinct because multicellular branching is uncommon, and cells migrated in a common direction with a leading multicellular strand. In comparison, collective mesenchymal organoids extend multicellular strands in multiple directions, and these strands commonly branch.
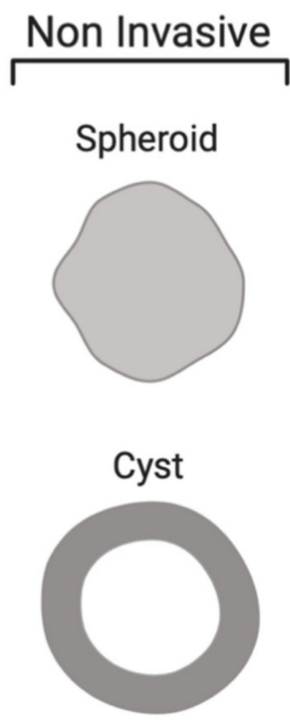

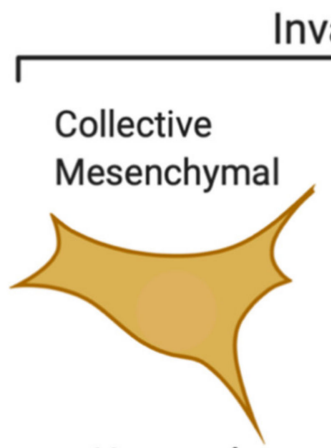

Neuronal

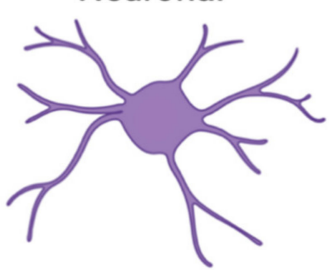

Invasive

\section{Elongated}

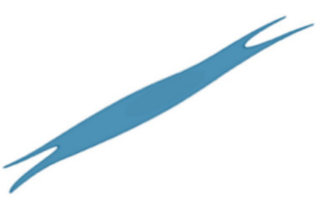

Protrusive

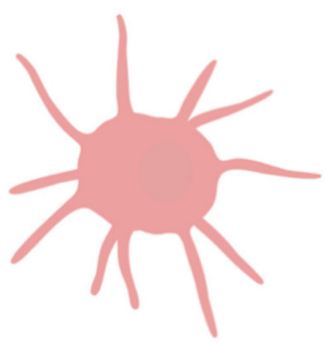

Figure 7. Schematic illustration of distinct morphological phenotypes observed in 3D invasion assays. Six distinct phenotypes in NB organoids isolated from PDXs were identified. Round organoids with no protrusions were termed "spheroid" and round organoids containing a lumen "cyst" due to their cyst-like appearance. Cells invading as collective strands with actin-rich protrusions (indicative of cells with mesenchymal traits) at the leading edge displayed a "collective mesenchymal" phenotype. These organoids contained strands invading in multiple directions. The "elongated" phenotype also displayed collective strand invasion, although multicellular streaming was present as well. Cells also migrated in a common direction leading with long actin-rich protrusions. "Neuronal" organoids invaded collectively as a dispersed network with transient cell-cell contacts; protrusions were neurite-like. The "protrusive" phenotype displayed a radial pattern of neurite-like protrusions, where cells migrated individually or were followed loosely by multicellular streams.

NB is derived from neural progenitor cells and displays neuronal behaviour; neurite formation is commonly seen in NB cells $[21,35]$. We identified "neuronal" organoids with dispersed cells extending neurite-like branches into the matrix. This strategy of invasion 
is morphologically comparable to that seen in glioma, where cells invade as a collective network with transient cell-cell interactions in 3D in vitro and in vivo models [22,23]. We also found "protrusive" organoids that maintained a round central cell mass while radially extending long thin actin-rich protrusions into the matrix, which may be unique to NB organoids. These protrusions often lacked nuclei, and when nuclei were present, they were individually migrating or loosely followed by multicellular streams. This phenotype may also be neuronal due to the long leading protrusion that is neurite-like and can be compared to organotypic cultures of glioblastoma that also display a radial pattern of invasion [36]. That being said, glioblastoma invasion appears less directional than that described here, and single cell dissemination was common in that model, while disseminating cells were only occasionally detected in NB organoids.

Phenotypic heterogeneity was also seen in non-invasive organoids (Figure 7). "Spheroid" organoids maintained a round cellular mass, while "cyst" organoids developed a lumenlike structure. Cysts were commonly found in Matrigel, suggesting that Matrigel also promotes diversity amongst non-invasive NB organoids. Cyst formation was described as a bi-layered epithelial structure that models the formation of epithelial ducts [25]. Although we did not determine whether the cyst-like structures were bi-layered, we speculate, given the origin of NB, that they may be in fact neuroepithelial in nature. Neuroepithelial cyst formation in 3D cultures was reported as a model of neural tube development in vivo [26]. Our results suggest that the intratumour heterogeneity of NB is retained within a PDX, with neuroepithelial, neuronal or mesenchymal cell populations. However, the proposed terminology will need to be confirmed in the future by mapping these categories to differing molecular pathways or histopathological observations.

\subsection{The Phenotypic Heterogeneity Seen in PDX Organoids Was Not Recapitulated in These Cell Lines}

NB cell lines grown in the same platform did not display cellular heterogeneity as seen in PDX organoids. NB cell lines tested herein may have intrinsic phenotypes that determine their migratory behaviour. EMT is an "intrinsic cell autonomous process" or a transient process in response to environmental stimuli [37]. Intrinsic EMT and stem cell-like phenotypes can be made irreversible due to genetic alterations [38]. The in vivo tumour microenvironment induced a distinct organoid phenotype in SH-SY5Y cells. SH-SY5Y cells were taken directly from a 2D monolayer culture where they were homogenously exposed to environmental factors. When we introduced SH-SY5Y cells to an in vivo tumour microenvironment, they grew as a tumour mass, which was heterogeneously exposed to such factors. In a hypoxia-sensing xenograft model, which separates hypoxic cells from their non-hypoxic counterparts, a distinct phenotype in hypoxic compared to non-hypoxic breast cancer cells was detected without depriving cells of oxygen in vitro [39]. The in vivo growth of cell lines (xenograft) was also linked to phenotypical changes in tumour-initiating cells in ovarian cancer [40]. We conclude that the in vivo tumour microenvironment increases the cellular heterogeneity in NB cell lines, but the selection for growth in vitro over many generations limits their invasion strategies.

\subsection{Matrigel Is the Preferred Substratum for NB Invasion}

We adapted an organoid model described for murine and human primary and metastatic breast tumours to study local NB cell invasion [41]. We grew organoids from NB PDXs in ECM hydrogels to monitor the dynamics of cell invasion in real-time. Collagen type-I gels but not Matrigel has been shown to promote the invasion and dissemination of malignant mammary epithelial cells [41,42]. Furthermore, in pancreatic cancer [43] and colon cancer, collagen type-I gels induce the expression of EMT genes [44]. Conversely, we showed that NB organoids preferentially invaded Matrigel.

During development, ECM components are classified into three distinct categories: permissive, non-permissive and inhibitory. Permissive ECM components, including laminin, fibronectin, collagen type-I and type-IV, are expressed along the migratory pathways of neural crest cells, the origin of NB, and promote cell motility. Certain 
laminin isoforms, fibronectin and collagen type-IV, are critical for the development of the neural crest [45]. NB cells migrate extensively in Matrigel, which contains these ECM molecules [27], which is in line with our findings.

The migration of neural crest cells is optimal in the basement membrane compared to collagen type I gels, and a competitive agonist for laminin (YIGSR) inhibits crest cell migration in Matrigel, suggesting that laminin is essential for neural crest cell motility [46]. Laminin-containing basal laminae are the preferred substratum for the migration of neural crest cells [47]. Laminin is also a promoter of neurite formation [48]. Thus, we speculate that the embryonal origin of NB may be explained by its preferential invasion of the laminin-rich matrix, Matrigel.

\subsection{Local Invasion of NB Cells Is Dependent on the Sample of Origin}

We showed that organoids isolated from 603x and Felix displayed an aggressive invasive behaviour in our ECM-mimicking cultures, in particular in Matrigel. In contrast, organoids isolated from $573 x$ and $424 x$ were non-invasive in both matrices tested. The NMA PDX, Felix, yielded organoids that displayed the most aggressive invasion. This may be due to the selection processes that occurred in the patient over multiple courses of therapy and the origin of the PDX, circulating tumour cells obtained post-mortem. The other three PDXs were established from samples taken at the time of diagnosis, prior to therapy. Clonal clusters derived from the NMA-amplified cell line, SH-SY5Y, and organoids derived from SH-SY5Y tumours also showed an aggressive invasion. As both a MYCN non-amplified cell line and a PDX displayed an aggressive behaviour, factors other than $M Y C N$ amplification may promote NB cell invasion. This is consistent with the large number of patients having high-risk non- $M Y C N$-amplified tumours that present with metastatic disease [49]. Our 3D model of local cell invasion is a valuable tool to study NB biology. By pairing NB organoids and $3 \mathrm{D}$ invasion assays, we may uncover genes and pathways that are involved in the local invasion of NB cells.

\subsection{Repression of MYCN Transcription Promotes Less Aggressive Cell Behaviour}

The amplification of MYCN is an unfavourable prognostic factor in NB and correlates with aggressive disease and worse outcome [31]. As expected, we found that MYCN-expressing cell clusters grew larger and displayed a more aggressive invasion. The literature supports our finding that MYCN expression is critical in the local invasion of NB cells. In transwell migration and invasion assays, higher levels of MYCN expression were correlated with increased cell motility and invasion [50]. In high-risk NB, upregulation of the EMT-promoting transcription factor TWIST1 was correlated with MYCN amplification and a MYCN transcriptional target [51]. MYCN has been shown to repress the transcription of the death receptor antagonist, Lifeguard (FAIM2), which is downregulated in high-risk NB. Repression of Lifeguard decreased cell adhesion and increased cell motility, promoting a more invasive phenotype [52]. Thus, MYCN transcription regulates aggressive cell behaviour.

\subsection{Benefits of 3D NB Cell Assays over Current Models of Local Invasion}

Our 3D model has many benefits over current models of local invasion, both in NB and other cancer types. Studies using organoid assays are relatively affordable, particularly when compared to murine models of metastasis. Our model offers superior optical accessibility and higher resolution imaging than in vivo models of local invasion. Local cell invasion was observed within a couple of days, another advantage over long-term in vivo studies. Although the development of PDXs can take some time, once established, using PDX-derived organoids greatly improves their experimental yield. There are many established NB PDXs available [10,15,53].

NB invasion in vitro has been mostly characterised by the scratch and transwell assays. We performed 3D invasion assays with NB cell lines to compare their behaviour to that observed in NB organoids and to published studies using transwell assays [54,55]. Cells 
were serum-starved for $24 \mathrm{~h}$ and transwells coated with basement membrane extract. Shankar's study included three of the cell lines used herein, namely, Kelly (NB 19), SHEP and Lan-1 [54]. In our 3D model, we observed highly aggressive behaviour for SHEP and Lan-1 cells, while Kelly cells were non-invasive. Conversely, Shankar et al. described Kelly cells as highly invasive and SHEP and Lan-1 cells as less invasive, with an invasion index of 7 for Kelly cells and invasion indices of $<1$ for SHEP and Lan- 1 cells. The stark contrast in cell behaviour between both assays may be due to the difference in dimensionality and the fact that our 3D model enables cells to migrate collectively. Differences in cell behaviour between 2D and 3D cultures are well known [56,57]. NB cells grown in 3D scaffolds display a 100-fold increased resistance to cisplatin compared to cells grown as 2D monolayers [58]. This chemotherapeutic resistance is comparable to that seen in orthotopic xenografts, highlighting the physiological relevance of 3D models. The phenotype and motility of glioma cells have been compared in 2D and 3D [59]. In 2D, glioma cells displayed a sheet-like morphology, non-directional migration and formation of random lamellipodium. Glioma cells invading 3D collagen gels were phenotypically similar to neural-progenitor cells, with a round cell body and a long leading process. This motility pattern was confirmed by cells grafted into organotypic brain slice cultures, suggesting that invasion in 3D closely resembles the in vivo scenario. Cellular heterogeneity among invasive cells was detected in both collagen gel and brain slice cultures but was absent in 2D.

Our results show that NB cells employed a range of distinct migration strategies. Notably, NB cells often migrated collectively as strands (collective mesenchymal) or as streams (protrusive, neuronal). However, transwell assays only assess the migration/invasion of individual NB cells. There is a lack of literature related to the modes of migration/invasion in NB in vivo, but some studies have assessed the migration of neural crest and melanoma cells. In the embryo, neural crest cells migrate as dense cohorts of cells that depend on three factors for directed migration: contact inhibition of locomotion, co-attraction and confinement [60]. Stream migration relies on leader cells at the invasive front with specific molecular signatures [61]. The presence of leader cells and the maintenance of cell-cell contacts are documented as requirements for trunk migration of neural crest cells [62]. In a process known as contact-stimulated migration, both neural crest and melanoma cells migrate far more effectively as a cohesive group [63]. Due to its origin, we suspect that collective cell migration may be the preferred mode of motility in NB. When modelling NB cell invasion, collective migration must be enabled, and thus, our 3D model is superior to the transwell assay. Our 3D model is more indicative of the in situ scenario than currently used 3D in vitro spheroid models of NB invasion [64]. In spheroids, cells do not display directional, multicellular and invasive structures. In fact, cell proliferation contributes largely to the spreading of spheroids. The phenotypic heterogeneity we observed during local invasion of organoids offers an advantage over current invasion assays.

Our 3D model also has some limitations. Given its origin, Matrigel varies from batch-to-batch. Its exact constituents are not well defined and may impact the signals that promote the observed cell behaviour [65]. Matrigel may not represent the human NB microenvironment. However, there is a lack of literature regarding the ECM composition in both NBs and healthy human embryos.

Our 3D model lacks the stromal tumour microenvironment. Cancer-associated fibroblasts (CAFs) and immune cells facilitate tumour cell invasion through ECM remodelling, physical interactions with cancer cells and pro-invasive stimuli [66,67]. In various coculture model systems, both CAFs and macrophages have been shown to promote the invasion and migration of tumour cells from many cancer types [16,68-73]. In future studies, further optimisation of our 3D model is required to facilitate 3D co-cultures. Although this will add a level of complexity to our assays, we will be able to explore the roles of stromal cells in local NB cell invasion.

In conclusion, we characterised six distinct phenotypes in organoids derived from human NB. In future studies, we will confirm that these phenotypes are molecularly 
distinct by profiling the differential gene expression and invasive gene signatures. Our 3D culture model is suited for the study of NB biology, including the impact of gene knockdown/induction on local matrix invasion.

\section{Materials and Methods}

\subsection{NB Cell Lines and Culture Conditions}

The neuroblastoma cell lines LAN-1, Kelly, CHP212, SH-SY5Y and SH-EP Tet21N [32], doxycycline-repressible (Tet-Off) MYCN gene cells, were cultured in corresponding cell culture media (Table S2.1 in File S2) containing 10\% heat-inactivated FBS (\#F0926, SigmaAldrich, St. Louis, MO, USA) with $50 \mathrm{U}$ of penicillin per $\mathrm{mL}$ and $0.1 \mathrm{mg}$ of streptomycin per $\mathrm{mL}$ at $37^{\circ} \mathrm{C}$ in a $5 \% \mathrm{CO}_{2}$ humidified atmosphere. All cell lines were authenticated by DNA profiling before use.

\subsection{Patient-Derived Xenograft Generation and Harvesting}

Neuroblastoma-specific PDX tumours, COG-N-424x, COG-N-573x, COG-N-603x and COG-N-Felix, were established in the laboratory of Dr. C. Patrick Reynolds the Children's Oncology Group (COG) and ALSF Childhood Cancer Repository (Sciences Center Texas Tech University Health, 2018). Briefly, selected PDXs were subcutaneously flank-engrafted into immuno-deficient mice (NOD.CB17-Prkdcscid/SzJ, NOD/SCID) and grown until tumours reached $1500 \mathrm{~mm}^{3}$, and tumours were harvested and cryopreserved with DMSO.

SH-SY5Y cells were subcutaneously xenografted into 6-8 week old female Hsd:Athymic Nude-Foxn1nu mice and grown until tumours reached $1000 \mathrm{~mm}^{3}$.

\subsection{Isolation of Neuroblastoma PDX Organoids}

NB PDX organoids were isolated using previously described techniques [41]. Briefly, the PDX tumours were minced with a scalpel and digested into tumour fragments by a combination of mechanical disruption and collagenase/trypsin digestion. These fragments were separated by differential centrifugation to remove both single cells and incompletely digest fragments. The final pellet was composed of similar size tumour fragments, each containing 30-60 cells, which we termed "organoids" (Figure S1.1 in File S1). NB organoids were assessed in the presence of murine stroma by co-immune fluorescence staining with DAPI and a neuroblastoma-specific marker using an anti- N-Myc (D1V2A) Rabbit mAb (\#84406, Cell Signaling Technology, Beverley, MA, USA) followed by labelling with Alexa Fluor $^{\circledR} 488$ Goat anti-Rabbit IgG secondary antibody (Figure S1.6 in File S1).

\subsection{Neuroblastoma Organoid Culture}

NB PDX-derived organoids or single cell suspensions were embedded in 3D Matrigel (354230; BD Biosciences) or rat-tail collagen I (\#354236; Corning) using 24-well black coverslip-bottomed plate (\#662892, Greiner Bio-One). Acid-solubilized rat-tail collagen I gels ( $3 \mathrm{mg} / \mathrm{mL}$ collagen I, pH 7-7.5) were prepared as described in [41]. For each matrix, organoids or single cells were mixed to yield a suspension of two or three organoids or cells $/ \mu \mathrm{L}$. Then, a $100-\mu \mathrm{L}$ mix was plated in each well on a $37^{\circ} \mathrm{C}$ heating block, followed by incubation at $37^{\circ} \mathrm{C}$ for $45 \mathrm{~min}$ to allow polymerisation. Tumour organoids were cultured in $1 \mathrm{~mL}$ of 2.5-nM FGF2 in organoid media (DMEM/F12, $50 \mathrm{U}$ of penicillin per $\mathrm{mL}, 0.1 \mathrm{mg}$ of streptomycin per $\mathrm{mL}, 1 \%$ insulin-transferrin-selenium). Cell clusters were cultured in a corresponding complete media (Table S2.1 in File S2).

\subsection{Time-Lapse Differential Interference (DIC) Contrast Microscopy}

NB PDX organoids or individual cells were live imaged using a LD Plan-Neofluar $20 \times / 0.4$ Korr Ph2 objective lens, a Zeiss AxioObserver Z1 and an Axio- Cam MRM camera. In general, images were captured every $20 \mathrm{~min}$ for 5 days beginning on the day 0 organoids were plated $(0 \mathrm{~h})$ maintaining temperature at $37^{\circ} \mathrm{C}$ and $\mathrm{CO}_{2}$ at $5 \%$. Cell line clusters were monitored and visualized daily after initial cell seeding. Some of the movies of NB 
PDX were collected using a Zeiss Axiovert S-100 microscope and a Cohu CCD camera, as previously reported [41]. Temperature was held at $37^{\circ} \mathrm{C}$ and $\mathrm{CO}_{2}$ at $5 \%$.

\subsection{Quantification of Organoid Growth and Invasion}

Growth and invasion of organoids and cell clusters were quantified by manually outlining their perimeters from DIC images and measuring the circularity with ImageJ (National Institutes of Health) (File S2). For growth, paired images for each organoid were obtained at 0 and $24 \mathrm{~h}$ after plating, and growth was represented as a fold change in projected area in $24 \mathrm{~h}$.

\subsection{Fluorescence Staining of 3D Hydrogels}

Once the imaging experiments were completed (120 h in culture), samples were washed with DPBS, fixed in $2 \%$ paraformaldehyde (PFA), permeabilized with $0.5 \%$ Triton X-100 and immediately blocked with 10\% FBS in DPBS. The samples were then incubated with phalloidin and DAPI to stain F-actin and cell nuclei, respectively. Images of organoids/cell clusters were taken using a laser-scanning confocal microscope (Zeiss LSM780, Jena, Germany).

\subsection{Statistical Analysis}

All statistical analyses were performed using Prism Software (GraphPad Software Inc, La Jolla, CA, USA). The relative growth of organoids/cell clusters across different matrices and different conditions was compared. This analysis involved comparing unmatched Gaussian populations where equal variances could not be assumed. Therefore, we used either unpaired $t$-tests with Welch's correction or Brown-Forsythe One-Way ANOVAs followed by T3 Dunnett post-hoc tests, depending on the number of groups, to compare the equality of means between populations. Statistical analyses were performed to compare the circularity of organoid/cell cluster populations at different time points. In this case, we had non-normally distributed data and thus performed non-parametric analyses using Kruskal-Wallis followed by Dunn's post hoc for multiple comparison between time-points. A value of $p<0.05$ was considered statistically significant.

\section{Conclusions}

This work demonstrates that $3 \mathrm{D}$ invasion assays are a suitable tool to study local invasion in NB. Various matrix compositions induced distinct cell behaviours, with Matrigel being the preferred substratum for local organoid invasion. Organoid invasion was PDX- and cell line-dependent and divided into six distinct phenotypes in PDX-derived organoids. In contrast, NB cell lines were phenotypically confined during invasion of the local ECM, while organoids isolated from cell line-derived xenografts displayed a broader range of phenotypes compared to clonal cell line clusters. The addition of FBS and bFGF induced the most aggressive cell behaviour and the widest range of phenotypes. In contrast, the repression of the prognostic NB marker, $M Y C N$, resulted in less aggressive cell behaviour. By pairing PDX-derived organoids and 3D invasion assays with high-resolution and real-time analysis, the molecular mechanisms that control local invasion are uncovered.

Supplementary Materials: The following are available online at https:/ / www.mdpi.com/2072-669 4/13/4/736/s1, File S1: Growth and invasion of PDX organoids, File S2: Materials and Methods.

Author Contributions: Conceptualisation, O.P.; Data curation, O.P. and C.G.; Formal analysis, C.G., N.G., D.L. and O.P.; Funding acquisition, O.P., C.P.R. and A.J.E.; Investigation, C.G., N.G. and O.P.; Methodology, C.G., A.J.E. and O.P.; Project administration, O.P.; Resources, C.P.R., A.J.E. and O.P.; Animal studies: M.H. and C.P.R.; Imaging, C.G., B.C. and O.P.; Visualisation, C.G., B.C. and O.P.; Writing-original draft, C.G. and O.P.; Writing-review and editing, C.G., D.L., C.P.R., A.J.E. and O.P. All authors have read and agreed to the published version of the manuscript. 
Funding: O.P. received support for this project through Fulbright-HRB Health Impact Scholar Award 2018/19, the National Children's Research Centre (Project grant (A/17/2)), Science Foundation Ireland (18/TIDA/6003) and RCSI Strategic Academic Recruitment (StAR) Programme. A.J.E. received support for this project through a grant from the National Institutes of Health/National Cancer Institute (U01CA217846). CPR received support from Alex's Lemonade Stand Foundation for the COG Childhood Cancer Repository and from the National Institutes of Health/National Cancer Institute (RO1 CA221957).

Institutional Review Board Statement: Neuroblastoma patient samples for establishing PDXs were obtained with informed consent via Children's Oncology Group protocols that were approved by the USA NIH central (national) IRB, the TTUHSC IRB and the IRBs of institutions caring for the patients. Growth and harvesting of PDXs was carried out at TTUHSC under a protocol approved continuously by the TTUHSC Institutional Animal Care and Use Committee (IACUC) since 2009 and approved at the time of these studies. TTUHSC IRB Protocol \# L09-041, the most recent approved on 9/23/2020.This research protocol for use of vertebrate animals in the Ewald Lab (MO20M234) was reviewed and approved by the Johns Hopkins University Animal Care and Use Committee on $7 / 27 / 2020$.

Informed Consent Statement: Not applicable. This study did not involve humans.

Data Availability Statement: Data is contained within the article or Supplementary Materials. The original raw image data are available upon request from the corresponding author olgapiskareva@ rcsi.com.

Conflicts of Interest: The authors declare no conflict of interest. The funders had no role in the design of the study; in the collection, analyses, or interpretation of data; in the writing of the manuscript, or in the decision to publish the results.

\section{References}

1. Steliarova-Foucher, E.; Colombet, M.; Ries, L.A.G.; Moreno, F.; Dolya, A.; Bray, F.; Hesseling, P.; Shin, H.Y.; Stiller, C.A.; IICC-3 Contributors. International incidence of childhood cancer, 2001-2010: A population-based registry study. Lancet Oncol. 2017, 18, 719-731. [CrossRef]

2. Force, L.M.; Abdollahpour, I.; Advani, S.M.; Agius, D.; Ahmadian, E.; Alahdab, F.; Alam, T.; Alebel, A.; Alipour, V.; Allen, C.A.; et al. The global burden of childhood and adolescent cancer in 2017: An analysis of the Global Burden of Disease Study 2017. Lancet Oncol. 2019, 20, 1211-1225. [CrossRef]

3. Smith, V.; Foster, J. High-Risk Neuroblastoma Treatment Review. Children 2018, 5, 114. [CrossRef]

4. Armstrong, A.E.; Danner-Koptik, K.; Golden, S.; Schneiderman, J.; Kletzel, M.; Reichek, J.; Gosiengfiao, Y. Late Effects in Pediatric High-risk Neuroblastoma Survivors After Intensive Induction Chemotherapy Followed by Myeloablative Consolidation Chemotherapy and Triple Autologous Stem Cell Transplants. J. Pediatr. Hematol. 2018, 40, 31-35. [CrossRef]

5. Nolan, J.; Frawley, T.; Tighe, J.; Soh, H.; Curtin, C.; Piskareva, O. Preclinical models for neuroblastoma: Advances and challenges. Cancer Lett. 2020, 474, 53-62. [CrossRef]

6. Ben-David, U.; Siranosian, B.; Ha, G.; Tang, H.; Oren, Y.; Hinohara, K.; Strathdee, C.A.; Dempster, J.; Lyons, N.J.; Burns, R.; et al. Genetic and transcriptional evolution alters cancer cell line drug response. Nature 2018, 560, 325-330. [CrossRef] [PubMed]

7. Marusyk, A.; Polyak, K. Tumor heterogeneity: Causes and consequences. Biochim. Biophys. Acta BBA Bioenerg. 2010, $1805,105-117$. [CrossRef] [PubMed]

8. Gengenbacher, N.; Singhal, M.; Augustin, H.G. Preclinical mouse solid tumour models: Status quo, challenges and perspectives. Nat. Rev. Cancer 2017, 17, 751-765. [CrossRef]

9. Kamili, A.; Atkinson, C.; Trahair, T.N.; Fletcher, J.I. Mouse models of high-risk neuroblastoma. Cancer Metastasis Rev. 2020, 39, 261-274. [CrossRef]

10. Braekeveldt, N.; Bexell, D. Patient-derived xenografts as preclinical neuroblastoma models. Cell Tissue Res. 2018, 372, $233-243$. [CrossRef] [PubMed]

11. Campbell, K.M.; Lin, T.; Zolkind, P.; Barnell, E.K.; Skidmore, Z.L.; Winkler, A.E.; Law, J.H.; Mardis, E.R.; Wartman, L.D.; Adkins, D.R.; et al. Oral Cavity Squamous Cell Carcinoma Xenografts Retain Complex Genotypes and Intertumor Molecular Heterogeneity. Cell Rep. 2018, 24, 2167-2178. [CrossRef]

12. Braekeveldt, N.; Wigerup, C.; Gisselsson, D.; Mohlin, S.; Merselius, M.; Beckman, S.; Jonson, T.; Börjesson, A.; Backman, T.; Tadeo, I.; et al. Neuroblastoma patient-derived orthotopic xenografts retain metastatic patterns and geno- and phenotypes of patient tumours. Int. J. Cancer 2014, 136, E252-E261. [CrossRef] [PubMed]

13. Braekeveldt, N.; Wigerup, C.; Tadeo, I.; Beckman, S.; Sandén, C.; Jönsson, J.; Erjefält, J.S.; Berbegall, A.P.; Börjesson, A.; Backman, T.; et al. Neuroblastoma patient-derived orthotopic xenografts reflect the microenvironmental hallmarks of aggressive patient tumours. Cancer Lett. 2016, 375, 384-389. [CrossRef] 
14. Zhao, X.; Liu, Z.; Yu, L.; Zhang, Y.; Baxter, P.; Voicu, H.; Gurusiddappa, S.; Luan, J.; Su, J.M.; Leung, H.-C.E.; et al. Global gene expression profiling confirms the molecular fidelity of primary tumor-based orthotopic xenograft mouse models of medulloblastoma. Neuro-Oncology 2012, 14, 574-583. [CrossRef]

15. Rokita, J.L.; Rathi, K.S.; Cardenas, M.F.; Upton, K.A.; Jayaseelan, J.; Cross, K.L.; Pfeil, J.; Egolf, L.E.; Way, G.P.; Farrel, A.; et al. Genomic Profiling of Childhood Tumor Patient-Derived Xenograft Models to Enable Rational Clinical Trial Design. Cell Rep. 2019, 29, 1675-1689.e9. [CrossRef] [PubMed]

16. Tomás-Bort, E.; Kieler, M.; Sharma, S.; Candido, J.B.; Loessner, D. 3D approaches to model the tumor microenvironment of pancreatic cancer. Theranostics 2020, 10, 5074-5089. [CrossRef] [PubMed]

17. Ilina, O.; Campanello, L.; Gritsenko, P.G.; Vullings, M.; Wang, C.; Bult, P.; Losert, W.; Friedl, P. Intravital microscopy of collective invasion plasticity in breast cancer. Dis. Model. Mech. 2018, 11, dmm034330. [CrossRef]

18. Wolf, K.; Wu, Y.I.; Liu, Y.; Geiger, J.; Tam, E.; Overall, C.M.; Stack, M.S.; Friedl, P. Multi-step pericellular proteolysis controls the transition from individual to collective cancer cell invasion. Nat. Cell Biol. 2007, 9, 893-904. [CrossRef]

19. Khalil, A.A.; Ilina, O.; Vasaturo, A.; Venhuizen, J.-H.; Vullings, M.; Venhuizen, V.; Bilos, A.; Figdor, C.G.; Span, P.N.; Friedl, P. Collective invasion induced by an autocrine purinergic loop through connexin-43 hemichannels. J. Cell Biol. 2020, 219. [CrossRef]

20. Alexander, S.; Weigelin, B.; Winkler, F.; Friedl, P. Preclinical intravital microscopy of the tumour-stroma interface: Invasion, metastasis, and therapy response. Curr. Opin. Cell Biol. 2013, 25, 659-671. [CrossRef]

21. Dwane, S.; Durack, E.; Kiely, P.A. Optimising parameters for the differentiation of SH-SY5Y cells to study cell adhesion and cell migration. BMC Res. Notes 2013, 6, 366. [CrossRef]

22. Gritsenko, P.G.; Atlasy, N.; Dieteren, C.E.J.; Navis, A.C.; Venhuizen, J.-H.; Veelken, C.; Schubert, D.; Acker-Palmer, A.; Westerman, B.A.; Wurdinger, T.; et al. p120-catenin-dependent collective brain infiltration by glioma cell networks. Nat. Cell Biol. 2020, 22, 97-107. [CrossRef] [PubMed]

23. Serres, E.; Debarbieux, F.; Stanchi, F.; Maggiorella, L.; Grall, D.; Turchi, L.; Burelvandenbos, F.; Figarellabranger, D.; Virolle, T.; Rougon, G.; et al. Fibronectin expression in glioblastomas promotes cell cohesion, collective invasion of basement membrane in vitro and orthotopic tumor growth in mice. Oncogene 2014, 33, 3451-3462. [CrossRef] [PubMed]

24. Friedl, P.; Gilmour, D. Collective cell migration in morphogenesis, regeneration and cancer. Nat. Rev. Mol. Cell Biol. 2009, 10, 445-457. [CrossRef] [PubMed]

25. Nguyen-Ngoc, K.-V.; Shamir, E.R.; Huebner, R.J.; Beck, J.N.; Cheung, K.J.; Ewald, A. 3D Culture Assays of Murine Mammary Branching Morphogenesis and Epithelial Invasion. In Tissue Morphogenesis: Methods and Protocols; Humana Press: New York, NY, USA, 2014; ISBN 9781493911646.

26. Zheng, Y.; Xue, X.; Resto-Irizarry, A.M.; Li, Z.; Shao, Y.; Zhao, G.; Fu, J. Dorsal-ventral patterned neural cyst from human pluripotent stem cells in a neurogenic niche. Sci. Adv. 2019, 5, eaax5933. [CrossRef] [PubMed]

27. Talbot, N.; Caperna, T.J. Proteome array identification of bioactive soluble proteins/peptides in Matrigel: Relevance to stem cell responses. Cytotechnology 2014, 67, 873-883. [CrossRef] [PubMed]

28. Sciences Center Texas Tech University Health Childhood Cancer Repository. Available online: http:/ /www.cccells.org/ (accessed on 5 January 2021).

29. Nguyen, T.H.; Koneru, B.; Wei, S.-J.; Chen, W.H.; Makena, M.R.; Urias, E.; Kang, M.H.; Reynolds, C.P. Fenretinide via NOXA Induction, Enhanced Activity of the BCL-2 Inhibitor Venetoclax in High BCL-2-Expressing Neuroblastoma Preclinical Models. Mol. Cancer Ther. 2019, 18, 2270-2282. [CrossRef]

30. Krytska, K.; Ryles, H.T.; Sano, R.; Raman, P.; Infarinato, N.R.; Hansel, T.D.; Makena, M.R.; Song, M.M.; Reynolds, C.P.; Mossé, Y.P. Crizotinib Synergizes with Chemotherapy in Preclinical Models of Neuroblastoma. Clin. Cancer Res. 2016, 22, 948-960. [CrossRef]

31. Huang, M.; Weiss, W.A. Neuroblastoma and MYCN. Cold Spring Harb. Perspect. Med. 2013, 3, a014415. [CrossRef]

32. Lutz, W.; Stöhr, M.; Schürmann, J.; Wenzel, A.; Löhr, A.; Schwab, M. Conditional expression of N-myc in human neuroblastoma cells increases expression of alpha-prothymosin and ornithine decarboxylase and accelerates progression into S-phase early after mitogenic stimulation of quiescent cells. Oncogene 1996, 13, 803-812.

33. Khoja, L.; Shenjere, P.; Hodgson, C.; Hodgetts, J.; Clack, G.; Hughes, A.; Lorigan, P.; Dive, C. Prevalence and heterogeneity of circulating tumour cells in metastatic cutaneous melanoma. Melanoma Res. 2014, 24, 40-46. [CrossRef] [PubMed]

34. Liu, X.; Zhang, Z.; Zhang, B.; Zheng, Y.; Zheng, C.; Liu, B.; Zheng, S.; Dong, K.; Dong, R. Circulating tumor cells detection in neuroblastoma patients by EpCAM-independent enrichment and immunostaining-fluorescence in situ hybridization. EBioMedicine 2018, 35, 244-250. [CrossRef]

35. Marler, K.J.M.; Kozma, R.; Ahmed, S.; Dong, J.-M.; Hall, C.; Lim, L. Outgrowth of Neurites from NIE-115 Neuroblastoma Cells Is Prevented on Repulsive Substrates through the Action of PAK. Mol. Cell. Biol. 2005, 25, 5226-5241. [CrossRef]

36. Fayzullin, A.; Tuvnes, F.A.; Skjellegrind, H.K.; Behnan, J.; Mughal, A.A.; Langmoen, I.A.; Vik-Mo, E.O. Time-lapse phenotyping of invasive glioma cells ex vivo reveals subtype-specific movement patterns guided by tumor core signaling. Exp. Cell Res. 2016, 349, 199-213. [CrossRef] [PubMed]

37. Elisha, Y.; Kalchenko, V.; Kuznetsov, Y.; Geiger, B. Dual role of E-cadherin in the regulation of invasive collective migration of mammary carcinoma cells. Sci. Rep. 2018, 8, 1-15. [CrossRef] [PubMed]

38. Brabletz, T. To differentiate or not-Routes towards metastasis. Nat. Rev. Cancer 2012, 12, 425-436. [CrossRef]

39. Kim, H.; Lin, Q.; Glazer, P.M.; Yun, Z. The hypoxic tumor microenvironment in vivo selects the cancer stem cell fate of breast cancer cells. Breast Cancer Res. 2018, 20, 1-15. [CrossRef] [PubMed] 
40. Stewart, J.M.; Shaw, P.A.; Gedye, C.; Bernardini, M.Q.; Neel, B.G.; Ailles, L.E. Phenotypic heterogeneity and instability of human ovarian tumor-initiating cells. Proc. Natl. Acad. Sci. USA 2011, 108, 6468-6473. [CrossRef]

41. Padmanaban, V.; Grasset, E.M.; Neumann, N.M.; Fraser, A.K.; Henriet, E.; Matsui, W.; Tran, P.T.; Cheung, K.J.; Georgess, D.; Ewald, A. Organotypic culture assays for murine and human primary and metastatic-site tumors. Nat. Protoc. 2020, 15, $2413-2442$. [CrossRef]

42. Nguyen-Ngoc, K.-V.; Cheung, K.J.; Brenot, A.; Shamir, E.R.; Gray, R.S.; Hines, W.C.; Yaswen, P.; Werb, Z.; Ewald, A. ECM microenvironment regulates collective migration and local dissemination in normal and malignant mammary epithelium. Proc. Natl. Acad. Sci. USA 2012, 109, E2595-E2604. [CrossRef]

43. Puls, T.J.; Tan, X.; Whittington, C.F.; Voytik-Harbin, S.L. 3D collagen fibrillar microstructure guides pancreatic cancer cell phenotype and serves as a critical design parameter for phenotypic models of EMT. PLoS ONE 2017, 12, e0188870. [CrossRef] [PubMed]

44. Vellinga, T.T.; den Uil, S.; Rinkes, I.H.; Marvin, D.; Ponsioen, B.; Alvarez-Varela, A.; Fatrai, S.; Scheele, C.; Zwijnenburg, D.A.; Snippert, H.; et al. Collagen-rich stroma in aggressive colon tumors induces mesenchymal gene expression and tumor cell invasion. Oncogene 2016, 35, 5263-5271. [CrossRef] [PubMed]

45. Perris, R.; Perissinotto, D. Role of the extracellular matrix during neural crest cell migration. Mech. Dev. 2000, 95, 3-21. [CrossRef]

46. Bilozur, M.E.; Hay, E.D. Neural crest migration in 3D extracellular matrix utilizes laminin, fibronectin, or collagen. Dev. Biol. 1988, 125, 19-33. [CrossRef]

47. Tosney, K.W.; Dehnbostel, D.B.; Erickson, C.A. Neural Crest Cells Prefer the Myotome's Basal Lamina over the Sclerotome as a Substratum. Dev. Biol. 1994, 163, 389-406. [CrossRef]

48. Flanagan, L.A.; Rebaza, L.M.; Derzic, S.; Schwartz, P.H.; Monuki, E.S. Regulation of human neural precursor cells by laminin and integrins. J. Neurosci. Res. 2006, 83, 845-856. [CrossRef]

49. Campbell, K.; Gastier-Foster, J.M.; Mann, M.; Naranjo, A.H.; Ms, C.V.R.; Bagatell, R.; Matthay, K.K.; London, W.B.; Irwin, M.S.; Shimada, H.; et al. Association ofMYCNcopy number with clinical features, tumor biology, and outcomes in neuroblastoma: A report from the Children's Oncology Group. Cancer 2017, 123, 4224-4235. [CrossRef]

50. Goodman, L.A.; Liu, B.C.S.; Thiele, C.J.; Schmidt, M.L.; Cohn, S.L.; Yamashiro, J.M.; Pai, D.S.M.; Ikegaki, N.; Wada, R.K. Modulation of N-myc expression alters the invasiveness of neuroblastoma. Clin. Exp. Metastasis 1997, 15, 130-139. [CrossRef]

51. Selmi, A.; De Saint-Jean, M.; Jallas, A.-C.; Garin, E.; Hogarty, M.D.; Bénard, J.; Puisieux, A.; Marabelle, A.; Valsesia-Wittmann, S. TWIST1 is a direct transcriptional target of MYCN and MYC in neuroblastoma. Cancer Lett. 2015, 357, 412-418. [CrossRef]

52. Planellsferrer, L.; Urresti, J.; Soriano, A.; Reix, S.; Murphy, D.M.; Ferreres, J.C.; Borras, F.E.; Gallego, S.M.; Stallings, R.L.; Moubarak, R.S.; et al. MYCN repression of Lifeguard/FAIM2 enhances neuroblastoma aggressiveness. Cell Death Dis. 2014, 5, e1401. [CrossRef]

53. Stewart, E.; Shelat, A.; Bradley, C.; Chen, X.; Federico, S.; Thiagarajan, S.; Shirinifard, A.; Bahrami, A.; Pappo, A.; Qu, C.; et al. Development and characterization of a human orthotopic neuroblastoma xenograft. Dev. Biol. 2015, 407, 344-355. [CrossRef]

54. Shankar, V.; Hori, H.; Kihira, K.; Lei, Q.; Toyoda, H.; Iwamoto, S.; Komada, Y. Mesenchymal Stromal Cell Secretome Up-Regulates $47 \mathrm{kDa}$ CXCR4 Expression, and Induce Invasiveness in Neuroblastoma Cell Lines. PLoS ONE 2015, 10, e0120069. [CrossRef]

55. Piskareva, O.; Harvey, H.; Nolan, J.P.; Conlon, R.; Alcock, L.; Buckley, P.; Dowling, P.; Henry, M.D.; O’Sullivan, F.; Bray, I.; et al. The development of cisplatin resistance in neuroblastoma is accompanied by epithelial to mesenchymal transition in vitro. Cancer Lett. 2015, 364, 142-155. [CrossRef] [PubMed]

56. Fraley, S.I.; Feng, Y.; Krishnamurthy, R.; Kim, D.-H.; Celedon, A.; Longmore, G.D.; Wirtz, D. A distinctive role for focal adhesion proteins in three-dimensional cell motility. Nat. Cell Biol. 2010, 12, 598-604. [CrossRef]

57. Meyer, A.S.; Hughes-Alford, S.K.; Kay, J.E.; Castillo, A.; Wells, A.; Gertler, F.B.; Lauffenburger, D.A. 2D protrusion but not motility predicts growth factor-induced cancer cell migration in 3D collagen. J. Cell Biol. 2012, 197, 721-729. [CrossRef] [PubMed]

58. Curtin, C.; Nolan, J.; Conlon, R.; Deneweth, L.; Gallagher, C.; Tan, Y.; Cavanagh, B.; Asraf, A.; Harvey, H.; Miller-Delaney, S.; et al. A physiologically relevant 3D collagen-based scaffold-neuroblastoma cell system exhibits chemosensitivity similar to orthotopic xenograft models. Acta Biomater. 2018, 70, 84-97. [CrossRef] [PubMed]

59. Fayzullin, A.; Sandberg, C.J.; Spreadbury, M.; Saberniak, B.M.; Grieg, Z.; Skaga, E.; Langmoen, I.A.; Vik-Mo, E.O. Phenotypic and Expressional Heterogeneity in the Invasive Glioma Cells. Transl. Oncol. 2019, 12, 122-133. [CrossRef]

60. Szabó, A.; Melchionda, M.; Nastasi, G.; Woods, M.L.; Campo, S.; Perris, R.; Mayor, R. In vivo confinement promotes collective migration of neural crest cells. J. Cell Biol. 2016, 213, 543-555. [CrossRef]

61. McLennan, R.; Schumacher, L.J.; Morrison, J.A.; Teddy, J.M.; Ridenour, D.A.; Box, A.C.; Semerad, C.L.; Li, H.; McDowell, W.; Kay, D.; et al. Neural crest migration is driven by a few trailblazer cells with a unique molecular signature narrowly confined to the invasive front. Development 2015, 142, 2014-2025. [CrossRef] [PubMed]

62. Richardson, J.; Gauert, A.; Montecinos, L.B.; Fanlo, L.; Alhashem, Z.M.; Assar, R.; Martí, E.; Kabla, A.; Härtel, S.; Linker, C. Leader Cells Define Directionality of Trunk, but Not Cranial, Neural Crest Cell Migration. Cell Rep. 2016, 15, 2076-2088. [CrossRef]

63. Thomas, L.A.; Yamada, K.M. Contact stimulation of cell migration. J. Cell Sci. 1992, 103, 1211-1214.

64. Mitchell, C.B.; O'Neill, G.M. Rac GTPase regulation of 3D invasion in neuroblastomas lacking MYCN amplification. Cell Adhes. Migr. 2016, 11, 68-79. [CrossRef] [PubMed]

65. Hughes, C.S.; Postovit, L.M.; Lajoie, G.A. Matrigel: A complex protein mixture required for optimal growth of cell culture. Proteomics 2010, 10, 1886-1890. [CrossRef] 
66. Attieh, Y.; Vignjevic, D.M. The hallmarks of CAFs in cancer invasion. Eur. J. Cell Biol. 2016, 95, 493-502. [CrossRef]

67. Hanley, C.J.; Henriet, E.; Sirka, O.K.; Thomas, G.; Ewald, A. Tumor-Resident Stromal Cells Promote Breast Cancer Invasion through Regulation of the Basal Phenotype. Mol. Cancer Res. 2020, 18, 1615-1622. [CrossRef]

68. Neri, S.; Ishii, G.; Hashimoto, H.; Kuwata, T.; Nagai, K.; Date, H.; Ochiai, A. Podoplanin-expressing cancer-associated fibroblasts lead and enhance the local invasion of cancer cells in lung adenocarcinoma. Int. J. Cancer 2015, 137, 784-796. [CrossRef]

69. Izar, B.; Joyce, C.E.; Goff, S.; Cho, N.L.; Shah, P.M.; Sharma, G.; Li, J.; Ibrahim, N.; Gold, J.; Hodi, F.S.; et al. Bidirectional cross talk between patient-derived melanoma and cancer-associated fibroblasts promotes invasion and proliferation. Pigment. Cell Melanoma Res. 2016, 29, 656-668. [CrossRef]

70. Puls, T.J.; Tan, X.; Husain, M.; Whittington, C.F.; Fishel, M.L.; Voytik-Harbin, S.L. Development of a Novel 3D Tumor-tissue Invasion Model for High-throughput, High-content Phenotypic Drug Screening. Sci. Rep. 2018, 8, 1-14. [CrossRef]

71. Smith, H.A.; Kang, Y. The metastasis-promoting roles of tumor-associated immune cells. J. Mol. Med. 2013, 91, 411-429. [CrossRef] [PubMed]

72. Wei, C.; Yang, C.; Wang, S.; Shi, D.; Zhang, C.; Lin, X.; Liu, Q.; Dou, R.; Xiong, B. Crosstalk between cancer cells and tumor associated macrophages is required for mesenchymal circulating tumor cell-mediated colorectal cancer metastasis. Mol. Cancer 2019, 18, 64. [CrossRef] [PubMed]

73. Dwyer, A.R.; Ellies, L.G.; Holme, A.L.; Pixley, F.J. A three-dimensional co-culture system to investigate macrophage-dependent tumor cell invasion. J. Biol. Methods 2016, 3, 49. [CrossRef] [PubMed] 